2011s-68

\title{
Capital-Labor Substitution, Structural Change and Growth
}

Francisco Alvarez-Cuadrado, Ngo Van Long

\begin{tabular}{c}
\hline Série Scientifique \\
Scientific Series
\end{tabular}

Montréal

Novembre 2011

(C) 2011 Francisco Alvarez-Cuadrado, Ngo Van Long. Tous droits réservés. All rights reserved. Reproduction partielle permise avec citation du document source, incluant la notice (C).

Short sections may be quoted without explicit permission, if full credit, including (C) notice, is given to the source.
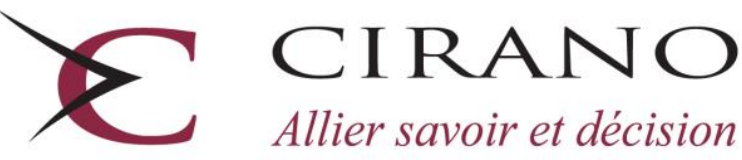

Allier savoir et décision

Centre interuniversitaire de recherche en analyse des organisations 


\section{CIRANO}

Le CIRANO est un organisme sans but lucratif constitué en vertu de la Loi des compagnies du Québec. Le financement de son infrastructure et de ses activités de recherche provient des cotisations de ses organisations-membres, d'une subvention d'infrastructure du Ministère du Développement économique et régional et de la Recherche, de même que des subventions et mandats obtenus par ses équipes de recherche.

CIRANO is a private non-profit organization incorporated under the Québec Companies Act. Its infrastructure and research activities are funded through fees paid by member organizations, an infrastructure grant from the Ministère du Développement économique et régional et de la Recherche, and grants and research mandates obtained by its research teams.

\section{Les partenaires du CIRANO}

\section{Partenaire majeur}

Ministère du Développement économique, de l'Innovation et de l'Exportation

\section{Partenaires corporatifs}

Autorité des marchés financiers

Banque de développement du Canada

Banque du Canada

Banque Laurentienne du Canada

Banque Nationale du Canada

Banque Royale du Canada

Banque Scotia

Bell Canada

BMO Groupe financier

Caisse de dépôt et placement du Québec

\section{CSST}

Fédération des caisses Desjardins du Québec

Financière Sun Life, Québec

Gaz Métro

Hydro-Québec

Industrie Canada

Investissements PSP

Ministère des Finances du Québec

Power Corporation du Canada

Rio Tinto Alcan

State Street Global Advisors

Transat A.T.

Ville de Montréal

\section{Partenaires universitaires}

École Polytechnique de Montréal

HEC Montréal

McGill University

Université Concordia

Université de Montréal

Université de Sherbrooke

Université du Québec

Université du Québec à Montréal

Université Laval

Le CIRANO collabore avec de nombreux centres et chaires de recherche universitaires dont on peut consulter la liste sur son site web.

Les cahiers de la série scientifique (CS) visent à rendre accessibles des résultats de recherche effectuée au CIRANO afin de susciter échanges et commentaires. Ces cahiers sont écrits dans le style des publications scientifiques. Les idées et les opinions émises sont sous l'unique responsabilité des auteurs et ne représentent pas nécessairement les positions du CIRANO ou de ses partenaires.

This paper presents research carried out at CIRANO and aims at encouraging discussion and comment. The observations and viewpoints expressed are the sole responsibility of the authors. They do not necessarily represent positions of CIRANO or its partners. 


\title{
Capital-Labor Substitution, Structural Change and Growth
}

\author{
Francisco Alvarez-Cuadrado*, Ngo Van Long ${ }^{\dagger}$
}

\begin{abstract}
Résumé / Abstract
Il y a un intérêt croissant pour les modèles qui combinent la croissance équilibrée au niveau agrégé avec des changements systématiques au niveau des secteurs industriels. Les explications initiales ont utilisé la variation de l'élasticité de la demande par rapport au revenu. Les modèles récents soulignent le rôle des facteurs de l'offre. Ngai et Pissarides (American Economic Review, 2008) se concentrent sur la différence entre les taux de croissance de la productivité des secteurs, tandis que Acemoglu and Guerrieri (Journal of Political Economy, 2008) considèrent la différence entre les proportions des facteurs de production. Nous explorons un cadre général qui englobe, comme des cas particuliers, ces deux mécanismes de l'offre. Notre modèle révèle une force motrice supplémentaire pour le changement structurel. Il s'agit de la différence entre les taux de substitution des facteurs de production. Lorsque la possibilité de combiner le capital et le travail varie selon les biens intermédiaires et que la production du bien final est Cobb-Douglas, la croissance de l'économie entraîne l'augmentation de la fraction du capital allouée au secteur ayant une élasticité de substitution plus élevée. Nous fournissions des faits compatibles à ce nouveau mécanisme.
\end{abstract}

Mots clés : Substitution entre capital et le travail, croissance equilibrée, changement structurel.

There is a growing interest in multi-sector models that combine aggregate balanced growth, consistent with the well-known Kaldor facts, with systematic changes in the relative importance of each sector, consistent with the Kuznets facts. Although variations in the income elasticity of demand across goods played an important role in the initial attempts, recent models stress the role of supply-side factors in this process of structural change. Along these lines, Ngai and Pissarides (American Economic Review, 2008) focus in differential productivity growth across sectors while Acemoglu and Guerrieri (Journal of Political Economy, 2008) stress differences in factor proportions and capital deepening. We explore a general framework that encompasses, as special cases, these two supply-side mechanisms. Our model uncovers an additional driving force for structural change based on differences in the degree of capital-labor substitutability. When the flexibility to combine capital and labor varies across intermediate goods and the final sector is Cobb-Douglas, as the economy grows the fraction of capital (labor) allocated to the sector with high elasticity of substitution increases (decreases). We provide some casual evidence consistent with this new mechanism.

Keywords: Capital-labor substitution, balanced growth, structural change.

Codes JEL: O40, 041, O30

\footnotetext{
* Department of Economics, McGill University, 855 Sherbrooke St West, Montreal, H3A 2T7, Canada. Email: Francisco-Alvarez-Cuadrado@mcgill.ca

${ }^{\dagger}$ CIRANO, Department of Economics, McGill University, 855 Sherbrooke St West, Montreal, H3A 2T7, Canada. Email: ngo.long@mcgill.ca
} 


\section{Introduction}

The theoretical literature on economic growth has been traditionally interested in models that exhibit a balanced growth path, a trajectory where the growth rate of output, the capital-output ratio, the return to capital, and the factor income shares are constant. It has become standard in this literature to impose restrictions on preferences and technology to be consistent with these Kaldor facts (Kaldor, 1963). Nonetheless behind this balanced process at the aggregate level there are systematic changes in the composition of output at a more disaggregated level, indicating a secular process of structural change. The seminal work of Clark (1940) and Kuznets (1966) already documented a facet of this structural transformation, particularly the continuous decrease in the share of agriculture in output and employment that accompanies long-run increases in income per capita. More recently, several authors (see for instance Kongsamut et al. 2001; Buera and Kaboski, 2011) drew attention to the increasing importance of the service sector. This second set of empirical regularities associated with the process of structural change has been dubbed by Kongsamut et al. (2001) as the Kuznets facts.

The recent years have witnessed several attempts to develop multi-sector growth models that integrate both sets of regularities, the Kaldor and Kuznets facts. This literature, inspired by the early contributions of Baumol (1967) and Matsuyama (1992), has identified several channels behind this process of structural transformation that still deliver a balanced growth path. Attending to these channels, one can classify these attempts into two categories: preference-driven and technology-driven structural change. ${ }^{1}$ In the first category (see for instance Kongsamut et al. (2001) or Foellmi and Zweimüller (2008)), structural change is driven by differences in the income elasticity of demand across goods. ${ }^{2}$ As capital accumulates and income rises these differences shift demand, and therefore resources and production, from goods with low demand elasticity, such as food or neccesities, to high demand elasticity goods, such as services or luxuries. In the second category, where technological differences across sectors play the dominant role, two alternative mechanisms have been identified. The first mechanism, recently formalized by Ngai and Pissarides (2007),

\footnotetext{
${ }^{1}$ Most papers assume a closed economy framework. In this context, the interaction between preferences and technology determine sectoral allocations. In an open economy, given world prices, sectoral allocations are only determined by the supply side of the model. See Matsuyama (1992) and Ventura (1997) for models of structural change in an open economy and Alvarez-Cuadrado and Poschke (2011) for the relevance of the closed-economy assumption in the context of structural change out of agriculture.

${ }^{2}$ There is a large body of work that assumes non-homotheticity as a source for structural change. See for instance Echeverria (1997), Laitner (2000), Caselli and Coleman (2001), Gollin, Parente and Rogerson (2007), and Restuccia and Duarte (2010).
} 
hereafter NP, works through differences in the rates of TFP growth across sectors. The second mechanism, explored by Acemoglu and Guerrieri (2008), hereafter AG, places its emphasis on sectoral differences in factor proportions, i.e. the elasticity of output to capital is different across sectors. Consequently, as sectoral levels of TFP diverge or capital accumulates, these differences generate a process of structural change and unbalanced growth at the disaggregate level that is still consistent with the Kaldor facts. ${ }^{3}$

The main objective of this paper is to explore an additional source for technology-driven structural change consistent with balanced growth at the aggregate level: we focus on sectoral differences in the elasticity of substitution between capital and labor. Intuitively, if the degree of flexibility to combine capital and labor varies across sectors, the secular change in the relative price of factors of production would lead to systematic changes in the sectoral composition of output. In this paper, we formalize this simple intuition. As we will demonstrate below, as the aggregate capital-labor ratio increases, the more flexible sector (i.e., the sector with the higher elasticity of factor substitution) is in a better position to substitute away from the relatively more expensive input, labor, into the relatively cheaper one, capital, than the less flexible one. As a result differences in the sectoral elasticity of substitution between capital and labor induce, in response to the secular increase in the aggregate capital stock, a process of structural reallocation of resources across sectors.

Our exercise was initially motivated by the trends documented in the factor income shares at the sectoral and industry levels. Zuleta and Young (2010) construct the labor income shares for agriculture, manufactures and services between 1958 and 1996 using data from the US 35-KLEM database (Jorgenson, 2007). Over this period the labor income shares within the agricultural and manufacturing sectors fell by roughly 31 and 8 percentage points respectively, while the labor income share within the service sector increased by 2 percentage points. This process was accompanied by a decrease in the agricultural and manufacturing shares of value added in GDP of 3 and 9 percentage points respectively while the service sector's share of value added in GDP increased by more than 16 percentage points. ${ }^{4}$ The above-mentioned trends in factor income shares at the sectoral level contrast with the relative constancy of their aggregate counterparts. ${ }^{5}$ There is further evidence of

\footnotetext{
${ }^{3}$ Baumol (1967) suggests several mechanisms behind structural change, specifically "innovations, capital accumulation, and economies of large scale" (pg. 415). Recently, Buera and Kaboski (2011) developed a model where structural change results from differences in the scale of productive units across sectors. This is yet another source of technology-driven structural change.

${ }^{4}$ Zuleta and Young (2010) exclude construction, mineral industries and government enterprises from their calculations.

${ }^{5}$ This relative constancy of the aggregate labor income share over long intervals of time is consistent with its medium and high frequency variation documented for instance by Blanchard (1997), Caballero and
} 
these uneven patterns at an even finer level of disaggregation. Figure 1 reproduces the labor income share for two selected US industries, chemicals and renting machinery and equipment, and for the aggregate economy. Not surprisingly, the same trends reported at the sectoral level are present at the industry level. The crucial role played by the elasticity of substitution for the evolution of the factor income shares suggests that this elasticity may also play an important role in the process of structural change. ${ }^{6}$

We present a two-sector version of the Solow model, along the lines of Jensen (2003). Final output is produced using a CES aggregator that combines two intermediate inputs, which are themselves sectoral outputs produced under two different CES production functions that use capital and labor. Under alternative parameter restrictions, we use this simple framework to capture the essence of the two different supply-side mechanisms stressed in the previous literature and to uncover a new one.

A first case, along the lines of the AG model, arises when the elasticity of substitution in the production of final output is less than one (i.e., the two intermediate inputs are not close substitutes) and sectoral outputs are produced using Cobb-Douglas technologies that differ in terms of capital intensity. In this case, as capital accumulates the fractions of capital and labor allocated to the more labor-intensive sector increase. Intuitively, as capital accumulates, if the fraction of resources allocated to each sector were kept constant, then output in the more capital-intensive sector would grow faster. This imbalance would cause a sharp drop in the relative price of the output of the fast growing sector, shifting resources (labor and capital) into the production of the labor-intensive intermediate good.

A second case, a version of the NP model, arises when the elasticity of substitution in the production of final output is less than one and sectoral outputs are produced using identical Cobb-Douglas technologies up to sector-specific rates of TFP growth. For the sake of illustration let the rate of TFP growth in sector 2 be higher than that in sector 1 . Then as the sectoral levels of TFP diverge, the fractions of capital and labor allocated to sector 1 must increase through time. Intuitively, since TFP growth is higher in sector 2, if the fractions of capital and labor allocated to each sector remained constant, output would grow faster in sector 2. Then its relative price would be falling more than proportionately, since both intermediate goods are strongly complementary in the production of final output, a version of Baumol's cost disease. As a result, capital and labor must move into the technologically

Hammour (1998) and Bentolila and Saint-Paul (2003).

${ }^{6}$ Recall that this elasticity was first introduced by Hicks in his seminal work, The Theory of Wages (1932), to explore the distribution of income between factors in a growing economy. Pitchford (1960) was the first to systematically analyze the relationship between the CES production function and the possibility of permanent growth in a neoclassical model of capital accumulation. 
laggard sector $1 .^{7}$

The third case, which illustrates our new mechanism, arises when the final output is produced under the Cobb-Douglas technology, and the sectoral technologies are identical except for the sectoral elasticity of substitution between capital and labor. For expositional purposes, let the elasticity of substitution of sector 2 -the flexible sector- exceed that of sector 1 . In this case, as the aggregate capital-labor ratio increases, the fractions of capital and labor allocated to the flexible sector move in opposite directions: the flexible sector absorbs more capital and releases labor. Intuitively, as capital accumulates, the ratio of the wage rate to the rental rate increases and the flexible sector will tend to substitute from the now more expensive input, labor, towards the relatively cheaper one, capital, at a higher rate than the less flexible sector 1 is able to do. In the context of this simple framework, we characterize a balanced growth path consistent with the Kaldor facts. In contrast to the NP and AG models, where sectoral factor allocations become asymptotically trivial, in the unequal capital-labor substitution model the long run fractions of employment and capital remain positive in both sectors. These results, derived under a constant saving rate, readily extend to an optimal saving environment.

Furthermore, it is worth noticing that the differences in the degree of factor substitution, although related to the differences in factor proportions stressed by the AG model, are clearly distinct, both conceptually and in terms of its implications as we have discussed in the previous paragraph. Conceptually, for a given factor price, factor proportions are determined by the interaction between the elasticity of substitution and the distributive parameter (the $\alpha$ in the Cobb-Douglas technology). AG focus on the sectoral differences in this latter parameter, while our model stresses the differences in the former.

Finally, the mechanism illustrated in this paper is related to that of Ventura (1997) and the recent literature on capital-skill complementarity initiated by Krusell, Ohanian, RiosRull and Violante (2000). Ventura (1997) presents a multi-country growth model where final output is produced combining two intermediate goods, one of which is produced using only capital and while the other uses only labor. There is free trade in both intermediate goods, although international factor movements are not permitted. In this context, as a country accumulates capital, resources are moved from labor-intensive to capital-intensive uses, a process of structural change, while international trade converts this excess production of capital-intensive goods into labor-intensive ones. Krusell et al. (2000) present a neoclassical

\footnotetext{
${ }^{7} \mathrm{~A}$ similar, but opposite, reasoning applies when the elasticity of substitution of the final sector exceeds unity, i.e. when sectoral outputs are close substitutes in the production of the final output, in either the NP model or the AG model.
} 
growth model where the elasticity of substitution is higher between capital equipment and unskilled labor than between capital equipment and skilled labor. As a result, as capital accumulates the wage for skilled workers increases at a higher rate than that of unskilled ones. They use this differential response of wages to rationalize the increase in skill premium over the last 30 years of the past century.

The paper is organized as follows. Section 2 sets out the basic model and explores the three cases we have just discussed. Section 3 presents the solution under optimal saving for the model with unequal sectoral capital-labor substitution. Section 4 provides suggestive evidence and explores some additional issues. The conclusions are summarized in section 5 while the Appendices include most of the proofs and some technical details.

\section{A general model of structural change}

We model a closed economy where a unique final good is produced under perfect competition by combining the output of two intermediate-good sectors, $Y_{1}$ and $Y_{2}$, according to a CES technology with elasticity of substitution $\varepsilon \in[0, \infty)$ :

$$
Y(t)=F\left(Y_{1}(t), Y_{2}(t)\right)=\left[\gamma Y_{1}(t)^{\frac{\varepsilon-1}{\varepsilon}}+(1-\gamma) Y_{2}(t)^{\frac{\varepsilon-1}{\varepsilon}}\right]^{\frac{\varepsilon}{\varepsilon-1}}
$$

where $\gamma \in(0,1)$ is the distributive share. ${ }^{8}$ Both intermediate-good sectors use two inputs, labor, $L$, and capital, $K$. The labor force grows at a rate $n$ and capital depreciates at a rate $\delta$. The aggregate resource constraint requires that the sum of consumption, $C$, and investment, $I$, be equal to output of the final good.

$$
\dot{K}(t)+\delta K(t)+C(t) \equiv I(t)+C(t)=Y(t)
$$

where the dot denotes the rate of change in a variable.

Under the assumption that a fixed fraction of output, $s$, is saved and invested every period, equation (2) yields the following law of motion for the capital stock,

$$
\dot{K}(t)=s Y(t)-\delta K(t)
$$

The two (intermediate) goods are produced competitively according to

$$
Y_{1}(t)=\left[\left(1-\alpha_{1}\right)\left(M_{1}(t) L_{1}(t)\right)^{\frac{\sigma_{1}-1}{\sigma_{1}}}+\alpha_{1} K_{1}(t)^{\frac{\sigma_{1}-1}{\sigma_{1}}}\right]^{\frac{\sigma_{1}}{\sigma_{1}-1}}
$$

\footnotetext{
${ }^{8}$ When $\varepsilon=1$, this equation becomes $Y=Y_{1}^{\gamma} Y_{2}^{1-\gamma}$.
} 


$$
Y_{2}(t)=\left[\left(1-\alpha_{2}\right)\left(M_{2}(t) L_{2}(t)\right)^{\frac{\sigma_{2}-1}{\sigma_{2}}}+\alpha_{2} K_{2}(t)^{\frac{\sigma_{2}-1}{\sigma_{2}}}\right]^{\frac{\sigma_{2}}{\sigma_{2}-1}}
$$

where $\alpha_{s} \in(0,1), \sigma_{s} \in[0, \infty), M_{s}, L_{s}$, and $K_{s}$ are respectively the distributive share, the elasticity of substitution, and the levels of technology, employment, and capital for sector s. ${ }^{9}$ Both inputs are fully utilized:

$$
\begin{aligned}
L_{1}(t)+L_{2}(t) & =L(t), \\
K_{1}(t)+K_{2}(t) & =K(t) .
\end{aligned}
$$

Technological progress in each sector is exogenous and exhibits a constant growth rate:

$$
\frac{\dot{M}_{s}(t)}{M_{s}(t)}=m_{s} \geqslant 0, \quad s=1,2 .
$$

This general set up includes, as special cases, several of the mechanisms described in the theoretical literature on structural change. First, AG present a model of structural change (and non-balanced growth) driven by differences in factor proportions and capital deepening. The distinctive features of their model are recovered by setting $\varepsilon \neq 1, \sigma_{1}=\sigma_{2}=1$ and $\alpha_{1} \neq \alpha_{2}$. Second, NP present a model of structural change driven by different sectoral TFP growth rates. Their model is recovered setting $\varepsilon \neq 1, \sigma_{1}=\sigma_{2}=1, \alpha_{1}=\alpha_{2}$ and $m_{2}>m_{1}$. Third, a novel mechanism, based on differences in the degree of capital-labor substitutability across sectors, is identified under the following parametric restrictions: $\varepsilon=1, \alpha_{1}=\alpha_{2}$ and $\sigma_{1} \neq \sigma_{2}$. In the next section we will derive some previous results and present new ones.

\subsection{Competitive solution}

Let us denote the rental rate, the wage rate, the prices of the intermediate goods and the price of the final good by $R \equiv r+\delta, w, p_{1}, p_{2}$ and $P$ respectively. ${ }^{10}$ We solve for the demand functions for the intermediate goods under perfect competition by maximizing output (1) subject to the zero profit condition $p_{1} Y_{1}+p_{2} Y_{2}=P Y$. The first order conditions for this problem, where $\lambda$ is the Lagrange multiplier, are given by,

$$
\begin{aligned}
\gamma\left(\frac{Y_{1}}{Y}\right)^{-\frac{1}{\varepsilon}} & =\lambda p_{1} \\
(1-\gamma)\left(\frac{Y_{2}}{Y}\right)^{-\frac{1}{\varepsilon}} & =\lambda p_{2}
\end{aligned}
$$

\footnotetext{
${ }^{9}$ Again, the possibility that $\sigma_{s}=1$ is admitted, for one or for both sectors.

${ }^{10}$ We drop the time indicators when there is no risk of ambiguity.
} 
where $\lambda=\frac{1}{P}$. These conditions imply the following demand functions, final good price (that we normalize to one) and sectoral prices,

$$
\begin{aligned}
Y_{1} & =\left(\frac{p_{1}}{\gamma P}\right)^{-\varepsilon} Y \\
Y_{2} & =\left(\frac{p_{2}}{(1-\gamma) P}\right)^{-\varepsilon} Y \\
P=p_{1} \frac{Y_{1}}{Y}+p_{2} \frac{Y_{2}}{Y} & =\left[\gamma^{\varepsilon} p_{1}^{1-\varepsilon}+(1-\gamma)^{\varepsilon} p_{2}^{1-\varepsilon}\right]^{\frac{1}{1-\varepsilon}} \equiv 1 \\
p_{1} & =\gamma\left(\frac{Y_{1}}{Y}\right)^{-\frac{1}{\varepsilon}} \\
p_{2} & =(1-\gamma)\left(\frac{Y_{2}}{Y}\right)^{-\frac{1}{\varepsilon}}
\end{aligned}
$$

that might be useful for future reference.

Following AG we break the solution of our problem into two steps. First, given the vector of state variables at any point in time, $\left(K, L, M_{1}, M_{2}\right)$, the allocation of factors across sectors is chosen to maximize final output, (1). This is the static problem. Second, given factor allocations at each date, the time path of the capital stock follows the law of motion (3). The dynamic problem consists of examining the stability of this process.

\subsection{The static problem}

At any point in time, the free mobility of capital and labor implies the equalization of the value of the marginal products of each factor

$$
\begin{gathered}
\gamma \alpha_{1}\left(\frac{Y}{Y_{1}}\right)^{\frac{1}{\varepsilon}}\left(\frac{Y_{1}}{K_{1}}\right)^{\frac{1}{\sigma_{1}}}=(1-\gamma) \alpha_{2}\left(\frac{Y}{Y_{2}}\right)^{\frac{1}{\varepsilon}}\left(\frac{Y_{2}}{K_{2}}\right)^{\frac{1}{\sigma_{2}}}=R \\
\gamma\left(1-\alpha_{1}\right)\left(\frac{Y}{Y_{1}}\right)^{\frac{1}{\varepsilon}}\left(\frac{Y_{1}}{L_{1}}\right)^{\frac{1}{\sigma_{1}}} M_{1}^{\frac{\sigma_{1}-1}{\sigma_{1}}}=(1-\gamma)\left(1-\alpha_{2}\right)\left(\frac{Y}{Y_{2}}\right)^{\frac{1}{\varepsilon}}\left(\frac{Y_{2}}{L_{2}}\right)^{\frac{1}{\sigma_{2}}} M_{2}^{\frac{\sigma_{2}-1}{\sigma_{2}}}=w
\end{gathered}
$$

The solution to the static problem amounts to the determinination of the sectoral allocations of capital and labor. It will prove useful to define the shares of capital and labor allocated to sector 1 as

$$
\kappa(t) \equiv \frac{K_{1}(t)}{K(t)} \quad \text { and } \quad \lambda(t) \equiv \frac{L_{1}(t)}{L(t)} .
$$

Combining (11), (12) and (13) we reach, 


$$
\begin{gathered}
\phi\left(\kappa, \lambda, K, L, M_{1}, M_{2}\right)=\kappa-(1-\kappa)^{\frac{\sigma_{1}}{\sigma_{2}}}\left[\frac{\gamma}{1-\gamma} \frac{\alpha_{1}}{\alpha_{2}} \frac{Y_{1}^{\frac{1}{\sigma_{1}}-\frac{1}{\varepsilon}}}{Y_{2}^{\frac{1}{\sigma_{2}}-\frac{1}{\varepsilon}}} K^{\frac{\sigma_{1}-\sigma_{2}}{\sigma_{1} \sigma_{2}}}\right]^{\sigma_{1}}=0 \\
\psi\left(\kappa, \lambda, K, L, M_{1}, M_{2}\right)=\lambda-(1-\lambda)^{\frac{\sigma_{1}}{\sigma_{2}}}\left[\frac{\left(1-\alpha_{1}\right)}{\left(1-\alpha_{2}\right)} \frac{\alpha_{2}}{\alpha_{1}} \frac{M_{1}^{\frac{\sigma_{1}-1}{\sigma_{1}}}}{M_{2}^{\frac{\sigma_{2}-1}{\sigma_{2}}}}(k)^{\frac{\sigma_{2}-\sigma_{1}}{\sigma_{1} \sigma_{2}}} \frac{\kappa^{\frac{1}{\sigma_{1}}}}{(1-\kappa)^{\frac{1}{\sigma_{2}}}}\right]^{\sigma_{1}}=0 \quad(15) \\
\text { where } \frac{Y_{1}^{\frac{1}{\sigma_{1}}-\frac{1}{\varepsilon}}}{Y_{2}^{\frac{1}{\sigma_{2}}-\frac{1}{\varepsilon}}}=\frac{\left[\left(1-\alpha_{1}\right)\left(M_{1} \lambda\right)^{\frac{\sigma_{1}-1}{\sigma_{1}}}+\alpha_{1}(\kappa k)^{\frac{\sigma_{1}-1}{\sigma_{1}}}\right]^{\frac{\varepsilon-\sigma_{1}}{\varepsilon\left(\sigma_{1}-1\right)}} L^{\frac{\sigma_{2}-\sigma_{1}}{\sigma_{1} \sigma_{2}}}}{\left[\left(1-\alpha_{2}\right)\left(M_{2}(1-\lambda)\right)^{\frac{\sigma_{2}-1}{\sigma_{2}}}+\alpha_{2}((1-\kappa) k)^{\frac{\sigma_{2}-1}{\sigma_{2}}}\right]^{\frac{\varepsilon-\sigma_{2}}{\varepsilon\left(\sigma_{2}-1\right)}}} \text { and } k \equiv \frac{K}{L} \text { is the }
\end{gathered}
$$
aggregate capital-labor ratio.

\subsubsection{Case 1: The Acemoglu-Guerrieri model}

AG present a model of structural change driven by differences in factor proportions and capital deepening. We set $\sigma_{1}=\sigma_{2}=1$ and assume sector 1 is more labor intensive, that is $\alpha_{2}>\alpha_{1}$. These sectoral differences in the capital income shares are the distinctive feature of the AG model. Furthermore, for expositional purposes, we focus on the case where both intermediate inputs are close complements in the production of final output, $\varepsilon<1$. For the moment, we restrict attention to the case where $M_{1}=M_{2}=M$ to abstract from the effect of differences in TFP across sectors. Under these restrictions, equations (14) and (15) become

$$
\begin{gathered}
\phi(\kappa, \lambda, k, M)=\kappa-\left[1+\frac{1-\gamma}{\gamma} \frac{\alpha_{2}}{\alpha_{1}}\left(\frac{Y_{1}}{Y_{2}}\right)^{\frac{1-\varepsilon}{\varepsilon}}\right]^{-1}=0 \\
\lambda=\left[1+\frac{\alpha_{1}}{\alpha_{2}} \frac{\left(1-\alpha_{2}\right)}{\left(1-\alpha_{1}\right)} \frac{(1-\kappa)}{\kappa}\right]^{-1}
\end{gathered}
$$

where $\frac{Y_{1}}{Y_{2}}=\lambda^{1-\alpha_{1}}(1-\lambda)^{-\left(1-\alpha_{2}\right)} \kappa^{\alpha_{1}}(1-\kappa)^{-\alpha_{2}}(k / M)^{\alpha_{1}-\alpha_{2}}$.

From equation (17) we get

$$
\frac{\partial \lambda}{\partial \kappa}=\frac{\alpha_{1}}{\alpha_{2}} \frac{\left(1-\alpha_{2}\right)}{\left(1-\alpha_{1}\right)}\left(\frac{\lambda}{\kappa}\right)^{2}>0
$$

which shows that at each point in time the fraction of labor allocated to sector 1 is increasing in the fraction of capital allocated to that sector.

Now we are in a position to evaluate how factor allocations change as the economy accumulates capital, i.e. as the aggregate capital labor-ratio increases. 
Proposition 1. Assume $\sigma_{1}=\sigma_{2}=1, \alpha_{2}>\alpha_{1}$ and $\varepsilon<1$. The fractions of capital and labor allocated to the labor-intensive sector increase as the as the aggregate capital-labor ratio increases:

$$
\frac{d \kappa}{d k}=\frac{1}{M} \frac{d \kappa}{d(k / M)}=\frac{(1-\varepsilon)\left(\alpha_{2}-\alpha_{1}\right)(1-\kappa) \kappa}{\left[1+(1-\varepsilon)\left(\alpha_{2}-\alpha_{1}\right)(\kappa-\lambda)\right] k}>0 .
$$

The reverse is true when $\varepsilon>1$.

Proof. See Appendix A

The intuition for this proposition is best understood by considering the effects of capital deepening in the absence of sectoral reallocation. Suppose that when the economy-wide capital-labor ratio increases, the sectoral allocation vector $(\lambda, \kappa)$ were kept unchanged, implying that the capital-labor ratio in each sector remained unchanged. Then the capitalintensive sector 2 would grow more than sector 1 because an equi-proportionate increase in capital raises the output of the capital-intensive sector by more. ${ }^{11}$ Since sectoral outputs are close complements (substitutes) in the production of the final good when $\varepsilon<1(\varepsilon>1)$, the relative price would shift in favor of (against) the sector that grows by a smaller proportion, the labor-intensive sector. This change in relative price induces a larger (smaller) fraction of resources to be allocated to the labor-intensive sector 1 .

\subsubsection{Case 2: The Ngai-Pissarides model}

NP present a model of structural change driven by differences in sectoral rates of TFP growth. The basic features of their model are recovered by setting $\sigma_{1}=\sigma_{2}=1$ and $\alpha_{2}=\alpha_{1}=\alpha$. As before we focus on the case where $\varepsilon<1$ and assume the rate of growth of TFP is higher in sector 2, i.e. $m_{2}>m_{1}$, so that $\frac{M_{2}}{M_{1}}$ grows through time. ${ }^{12}$ These differences in sectoral TFP growth rates are the distinctive feature of the NP model. Notice that under these restrictions equation (15) becomes,

$$
\psi(\kappa, \lambda)=\lambda-(1-\lambda) \frac{\kappa}{(1-\kappa)}=0
$$

which implies that $\lambda=\kappa$ hence capital-labor ratios are the same in both sectors,

$$
\frac{K_{1}}{L_{1}}=\frac{K_{2}}{L_{2}}=\frac{K}{L}
$$

\footnotetext{
${ }^{11}$ This is reminiscent of the Rybczinski Theorem in international trade theory.

${ }^{12} \mathrm{NP}$ model an arbitrary number of sectors that produce a capital good and a variety of final consumption goods. They define the instantaneous utility function as a constant elasticity aggregator of these consumption goods. In our framework, the constant elasticity aggregator is replaced by the production function for final output, and our two intermediate inputs play the role of their differentiated varieties.
} 
As a result equation (14) becomes,

$$
\kappa=\left[1+\left(\frac{1-\gamma}{\gamma}\right)^{\varepsilon}\left(\frac{M_{2}}{M_{1}}\right)^{(1-\alpha)(\varepsilon-1)}\right]^{-1}
$$

Now we are in a position to evaluate how the fraction of capital (and labor) in the slow TFPgrowth sector, sector 1 , changes in response to the differential productivity growth across sectors.

Proposition 2. Assume $\sigma_{1}=\sigma_{2}=1, \alpha_{2}=\alpha_{1}=\alpha, m_{2}>m_{1} \geq 0$, and $\varepsilon<1$. Then the fractions of capital and labor allocated to the technologically sluggish sector, sector 1 , increase as its relative level of total factor productivity decreases, i.e. as sector 1's TFP falls relative to sector 2 's TFP.

$$
\frac{\partial \kappa}{\partial\left(\frac{M_{2}}{M_{1}}\right)}=\kappa^{2}\left(\frac{1-\gamma}{\gamma}\right)^{\varepsilon}(1-\alpha)(1-\varepsilon)\left(\frac{M_{2}}{M_{1}}\right)^{(1-\alpha)(\varepsilon-1)-1}>0
$$

The reverse is true when $\varepsilon>1$.

Proof. The result is obtained by differentiating (21).

The intuition for this proposition is similar to the previous one. Suppose that when the relative TFP grows there were no sectoral reallocation, i.e., $(\lambda, \kappa)$ were kept unchanged, implying that the capital-labor ratio in each sector remained unchanged. Then the high TFPgrowth sector 2 would expand its output relative to sector 1 . Since the sectoral outputs are very complementary (substitutable) in the production of the final good when $\varepsilon<1(\varepsilon>1)$, the relative price of the good produced in the stagnant sector would increase more (less) than proportionally, inducing a larger (smaller) fraction of both capital and labor to be reallocated into that sector. Notice that, as in the AG model, the fractions of capital and labor allocated to a sector either increase or decrease, but within each sector, both move in the same direction.

\subsubsection{Case 3: A model of unequal sectoral capital-labor substitution}

Now, we turn to explore whether sectoral differences in the degree of capital-labor substitutability could lie behind the patterns of sectoral reallocation. We impose the following restrictions. First we close the channels explored in the previous models by setting $\varepsilon=1$. As it is clear from (19) and (22) when the production function for final output is Cobb-Douglas neither capital deepening combined with differences in capital intensity nor differential TFP 
growth lead to any sectoral reallocation. Second, we set $\alpha_{2}=\alpha_{1}=\alpha$. Finally, the distinctive feature of this model is the sectoral differences in the elasticity of substitution between the two factors of production. For the sake of tractability we restrict sector 1 to be Cobb-Douglas and therefore we set $\sigma_{2} \neq \sigma_{1}=1$.

Now equations (14) and (15) become,

$$
\begin{gathered}
\phi\left(\kappa, \lambda, k, M_{1}, M_{2}\right)=\kappa-(1-\kappa)^{\frac{1}{\sigma_{2}}} \frac{\gamma}{1-\gamma}\left(\frac{Y_{2}}{K}\right)^{\frac{\sigma_{2}-1}{\sigma_{2}}}=0 \\
\psi\left(\kappa, \lambda, k, M_{1}, M_{2}\right)=\lambda-(1-\lambda)^{\frac{1}{\sigma_{2}}} M_{2}^{\frac{1-\sigma_{2}}{\sigma_{2}}}(k)^{\frac{\sigma_{2}-1}{\sigma_{2}}} \frac{\kappa}{(1-\kappa)^{\frac{1}{\sigma_{2}}}}=0
\end{gathered}
$$

where

$$
\left(\frac{Y_{2}}{K}\right)^{\frac{\sigma_{2}-1}{\sigma_{2}}}=(1-\alpha)\left(\frac{(1-\lambda) M_{2}}{k}\right)^{\frac{\sigma_{2}-1}{\sigma_{2}}}+\alpha(1-\kappa)^{\frac{\sigma_{2}-1}{\sigma_{2}}}
$$

Combining (23), (24) and (25) we reach, after some tedious manipulation, the following relationship between the shares of capital and labor in sector 1 ,

$$
\lambda=\lambda(\kappa)=\frac{\gamma(1-\alpha) \kappa}{\kappa-\alpha \gamma} \quad \text { with } \quad \frac{d \lambda}{d \kappa}=-\left(\frac{\alpha}{1-\alpha}\right)\left(\frac{\lambda(\kappa)}{\kappa}\right)^{2}<0
$$

(see Appendix $\mathrm{C}$ for a complete derivation). This is an important result that contrasts with those of the two previous models. Equation (26) shows that the fraction of labor in each sector is a decreasing function on the fraction of capital in that same sector.

Furthermore since $\lambda \leq 1$ and $\kappa \leq 1$ equation (26) determines the following feasibility regions for the sectoral factor allocations, ${ }^{13}$

$$
\begin{gathered}
\lambda \in[\underline{\lambda}, 1] \quad \text { where } \quad 0<\underline{\lambda} \equiv \frac{\gamma(1-\alpha)}{1-\alpha \gamma}<1 \\
\kappa \in[\underline{\kappa}, 1] \quad \text { where } \quad 0<\underline{\kappa} \equiv \frac{\alpha \gamma}{1-\gamma+\alpha \gamma}<1 .
\end{gathered}
$$

Now we are in a position to evaluate how the fractions of capital and labor in the less flexible sector respond to changes in the state variables.

Proposition 3. Assume $\varepsilon=1, \alpha_{2}=\alpha_{1}=\alpha$ and, for the sake of exposition, let sector 1 be the less flexible sector, i.e. $\sigma_{2}>\sigma_{1}=1$. Then the fraction of capital allocated to the less flexible sector 1 falls (increases) as the economy's aggregate capital-labor ratio increases (TFP in Sector 2 increases), while its fraction of labor increases (falls). In particular,

\footnotetext{
${ }^{13}$ Similarly, using (17) and (20) one can determine the feasibility regions for the sectoral factor allocations in the AG and NP models respectively. In both cases these regions span the whole unit interval, including both end-points.
} 


$$
\begin{gathered}
\frac{\partial \kappa}{\partial k}=\frac{\left(1-\sigma_{2}\right)}{\sigma_{2} G(\kappa) k}<0 \\
\frac{\partial \lambda}{\partial k}=\left(\frac{\alpha}{1-\alpha}\right)\left(\frac{\lambda(\kappa)}{\kappa}\right)^{2} \frac{\left(\sigma_{2}-1\right)}{\sigma_{2} G(\kappa) k}>0 \\
\frac{\partial \kappa}{\partial M_{2}}=\frac{\left(\sigma_{2}-1\right)}{\sigma_{2} G(\kappa) M_{2}}>0 \\
\frac{\partial \lambda}{\partial M_{2}}=\left(\frac{\alpha}{1-\alpha}\right)\left(\frac{\lambda(\kappa)}{\kappa}\right)^{2} \frac{\left(1-\sigma_{2}\right)}{\sigma_{2} G(\kappa) M_{2}}<0 \\
\frac{\partial \kappa}{\partial M_{1}}=\frac{\partial \lambda}{\partial M_{1}}=0
\end{gathered}
$$

where

$$
G(\kappa) \equiv\left[\frac{1}{\sigma_{2}(1-\lambda(\kappa))}+\frac{1}{\lambda(\kappa)}\right]\left(\frac{\lambda(\kappa)}{\kappa}\right)^{2}\left(\frac{\alpha}{1-\alpha}\right)+\left[\frac{1}{\kappa}+\frac{1}{\sigma_{2}(1-\kappa)}\right]
$$

Notice that the inequality signs in (29)-(32) are reversed when sector 1 is the more flexible one, i.e. $\sigma_{2}<\sigma_{1}=1$.

Proof. Combining (24) with (26) and taking logarithms we reach,

$$
\frac{1-\sigma_{2}}{\sigma_{2}} \ln k=\frac{1}{\sigma_{2}} \ln (1-\lambda(\kappa))-\ln \lambda(\kappa)+\frac{1-\sigma_{2}}{\sigma_{2}} \ln M_{2}+\ln \kappa-\frac{1}{\sigma_{2}} \ln (1-\kappa)
$$

The result is obtained differentiating (35) using (26).

Remarks on Proposition 3: (i) As $\kappa \rightarrow \underline{\kappa}, \lambda(\kappa) \rightarrow 1$ and hence $G(\kappa) \rightarrow \infty$. This implies that as $\kappa \rightarrow \underline{\kappa}$, both $\frac{\partial \kappa}{\partial k}$ and $\frac{\partial \lambda}{\partial k} \rightarrow 0$. (ii) When the aggregate capital-labor ratio increases, both sectoral capital-labor ratios, $k_{1} \equiv K_{1} / L_{1}$ and $k_{2} \equiv K_{2} / L_{2}$, also increase. (See the Appendix C for a proof.)

In order to understand the logic of Proposition 3 let us first concentrate on the effects of capital accumulation on the fractions of capital and labor allocated to each sector. As the economywide capital-labor ratio increases, the ratio of wage rate to rental rate increases. As a result, the more flexible sector tends to substitute away from the now more expensive input, labor, towards the relatively cheaper one, capital, at a higher rate than the less flexible sector 1 is able to do. Consequently the fraction of capital allocated to the more flexible sector -sector 2- increases while its share on labor employment decreases. Given full employment, the converse is true for the less flexible sector 1. Changes in TFP in the Cobb-Douglas 
sector, $M_{1}$, leave the ratio of factor prices unchanged. In contrast, increases in $M_{2}$, the level of TFP in the more flexible sector, lower the price of effective labor, and, as a result, the wage-rental ratio decreases. As before the more flexible sector 2, taking advantage of this change in relative factor prices, moves into a more labor-intensive mode of production. The response of input allocations in the model with differential capital-labor substitutability contrasts with the responses in the previous two models. In both AG and NP, one of the sectors was either shedding both capital and labor, or absorbing both, while, in this model, each sector reduces its share of one of the factors while increases its share of the other.

Finally, and again in contrast to the previous two models, notice that structural change takes place despite that the production function for the final output is Cobb-Douglas, i.e. sectoral reallocations take place even when the expenditure shares on the intermediate goods remain constant.

\subsection{The dynamic problem}

Now we turn to the characterization of the solution for the dynamic problem under our three alternative parameterizations. For added generality, we now allow the sectoral TFP growth rates to be different in the AG model, similar to what we have assumed for the NP model. We assume that $m_{2}>m_{1} \geq 0$. Under this restriction, sector 1 is the asymptotically dominant sector in terms of employment of both factors. This results from the fact that when $\varepsilon<1$ intermediate inputs are highly complementary in the production of final output and therefore the slower-growing sector will determine the asymptotic growth rate of final output.

In all three models, we introduce the key variable,

$$
\chi(t) \equiv \frac{K(t)}{L(t) M_{1}(t)}
$$

which is aggregate capital per head deflated by the TFP level of the technologically laggard sector. Then, using (3) we reach,

$$
\widehat{\chi} \equiv \frac{\dot{\chi}(t)}{\chi(t)}=\frac{\dot{K}(t)}{K(t)}-n-m_{1}=\frac{I(t)}{K(t)}-n-m_{1}-\delta=s \frac{Y(t)}{K(t)}-n-m_{1}-\delta
$$

While the dynamic equation (37) is common to all three models, we will see below that the expression for $Y(t) / K(t)$ differs across models. 


\subsubsection{Case 1: Dynamics of the Acemoglu-Guerrieri model}

Recall that this case arises when $\sigma_{1}=\sigma_{2}=1$ and $\alpha_{2}>\alpha_{1}$. Again, for expositional purposes we will focus in the case where $\varepsilon<1$ and following our previous discussion we assume $m_{2}>m_{1} \geq 0 .{ }^{14}$

Proposition 4. Under the stated assumptions and given the initial conditions, $\chi(0)=$ $\chi_{0}$ and $\kappa(0)=\kappa_{0}$, the solution to the dynamic problem satisfies the following system of differential equations,

$$
\begin{gathered}
\hat{\chi}(t)=s \eta(t) \lambda(t)^{1-\alpha_{1}} \kappa(t)^{\alpha_{1}} \chi(t)^{\alpha_{1}-1}-\left(\delta+n+m_{1}\right) \\
\hat{\kappa}(t)=\frac{(1-\kappa(t))\left(\alpha_{2}-\alpha_{1}\right)\left(\hat{\chi}(t)+m_{2}\right)}{(1-\varepsilon)^{-1}+\left(\alpha_{2}-\alpha_{1}\right)(\lambda(t)-\kappa(t))}
\end{gathered}
$$

where $\eta(t)=\gamma^{\frac{\varepsilon}{\varepsilon-1}}\left[1+\frac{\alpha_{1}}{\alpha_{2}} \frac{(1-\kappa(t))}{\kappa(t)}\right]^{\frac{\varepsilon}{\varepsilon-1}}$ and $\lambda(t)$ is given by $(17)$.

Proof. See Appendix A

Let us define the following growth rates for the variables of interest (using an asterisk for their asymptotic, steady state, counterparts),

$$
\begin{aligned}
\frac{\dot{L}_{s}(t)}{L_{s}(t)} & \equiv n_{s}(t), \quad \frac{\dot{K}_{s}(t)}{K_{s}(t)} \equiv z_{s}(t), \quad \frac{\dot{Y}_{s}(t)}{Y_{s}(t)} \equiv g_{s}(t), \quad \text { for } s=1,2, \\
\frac{\dot{K}(t)}{K(t)} & \equiv z(t), \quad \frac{\dot{Y}(t)}{Y(t)} \equiv g(t)
\end{aligned}
$$

We define a "constant growth path" (CGP) as a solution along which the aggregate capital-output ratio, $\frac{K}{Y}$, is constant. ${ }^{15}$ Then we have the following characterization of the unique (non-trivial) CGP.

Theorem 1. Under the stated assumptions, there exists a unique (non-trivial) CGP with

\footnotetext{
${ }^{14}$ Notice that if $m_{2}=m_{1}=m$ then by normalization we can write $M_{1}=M_{2}=M$, and using Proposition 1 , we can treat $\kappa$ (and hence $\lambda$ ) as a function of $\chi$. We would then face a single first order differential equation. In the derivations that follow we deal with the more general case where $m_{2}>m_{1} \geq 0$.

${ }^{15}$ Our definition is equivalent to that of AG and Kongsamut et al. (2001). The former paper requires a constant consumption growth rate in a model of endogenous saving. The latter defines a "generalized balanced growth path" as a trajectory along which the real interest rate is constant.
} 
the following properties,

$$
\begin{aligned}
& \chi^{*}=\left(\frac{s \gamma^{\frac{\varepsilon}{\varepsilon-1}}}{\delta+n+m_{1}}\right)^{\frac{1}{1-\alpha_{1}}}, \quad \kappa^{*}=\lambda^{*}=1, \\
& g^{*}=z^{*}=g_{1}^{*}=z_{1}^{*}=n+m_{1}, \\
& g_{2}^{*}=g^{*}+\varepsilon\left(1-\alpha_{2}\right)\left(m_{2}-m_{1}\right), \quad z_{2}^{*}=g^{*}-(1-\varepsilon)\left(1-\alpha_{2}\right)\left(m_{2}-m_{1}\right), \\
& n_{1}^{*}=n, \quad n_{2}^{*}=n-(1-\varepsilon)\left(1-\alpha_{2}\right)\left(m_{2}-m_{1}\right) .
\end{aligned}
$$

The steady state associated with this CGP is locally stable.

Proof. See Appendix Al

A couple of results require further comment. First, the two intermediate sectors grow at different rates even along the CGP if $m_{2} \neq m_{1}$. In this sense growth is non-balanced. This unbalanced growth arises from the differential TFP growth rates across sectors. Notice that if both sectoral TFP grew at the same rate, $m_{1}=m_{2}=m$, then the steady state sectoral per capita growth rates would coincide with the exogenous rate of TFP growth, $m .{ }^{16}$ Second, although the fractions of inputs in the asymptotically dominant sector $1, \kappa$ and $\lambda$, tend in the limit to one, sector 2 grows faster than the rest of the economy along the CGP. In this sense both sectors will be permanently operative although the shares of capital and employment in sector 2 become asymptotically trivial. Finally, as the economy asymptotically reaches the CGP the process of sectoral reallocation ceases.

Remark on non-monotone behavior: A phase diagram analysis of the system of differential equations (38) and (39) reveals that the time path of $\chi$ and $\kappa$ can be nonmonotone. (See Appendix A.)

\subsubsection{Case 2: Dynamics of the Ngai-Pissarides model}

Recall that this case arises when $\sigma_{1}=\sigma_{2}=1$ and $\alpha_{2}=\alpha_{1}=\alpha$. As before we restrict attention to the case where $\varepsilon<1$. Furthermore, let $m_{2}>m_{1}$ so that sector 1 is the asymptotically dominant sector for the same reasons than in the previous model.

Proposition 5. Under the stated assumptions and given the initial conditions, $\chi(0)=$ $\chi_{0}$ and $\kappa(0)=\kappa_{0}$, the competitive equilibrium satisfies the following pair of differential equations,

$$
\hat{\chi}(t)=s \xi(t) \chi(t)^{\alpha_{1}-1}-\left(\delta+n+m_{1}\right)
$$

\footnotetext{
${ }^{16}$ Notice that the condition for balanced growth in the original AG model is $m_{1} / \alpha_{1}=m_{2} / \alpha_{2}$ rather than $m_{1}=m_{2}$ since AG specify TFP as Hicks neutral while in our equations (4) and (5) we model TFP as Harrod neutral.
} 


$$
\hat{\kappa}(t)=(1-\kappa(t))(1-\alpha)(1-\varepsilon)\left(m_{2}-m_{1}\right)
$$

where $\xi(t) \equiv\left[\gamma \kappa(t)^{\frac{\varepsilon-1}{\varepsilon}}+(1-\gamma)\left(\left(\frac{M_{2}(t)}{M_{1}(t)}\right)^{1-\alpha}(1-\kappa(t))\right)^{\frac{\varepsilon-1}{\varepsilon}}\right]^{\frac{\varepsilon}{\varepsilon-1}}$.

Proof. See Appendix A

Let's turn now to the characterization of the constant growth path.

Theorem 2. Under the stated assumptions, there exists a unique (non-trivial) CGP with the following properties,

$$
\begin{array}{ll}
\chi^{*} & =\left(\frac{s \gamma^{\frac{\varepsilon}{\varepsilon-1}}}{\delta+n+m_{1}}\right)^{\frac{1}{1-\alpha_{1}}}, \quad \kappa^{*}=\lambda^{*}=1, \\
g^{*} & =z^{*}=g_{1}^{*}=z_{1}^{*}=n+m_{1}, \\
g_{2}^{*} & =g^{*}+\varepsilon(1-\alpha)\left(m_{2}-m_{1}\right), \quad z_{2}^{*}=g^{*}-(1-\varepsilon)(1-\alpha)\left(m_{2}-m_{1}\right), \\
n_{1}^{*} & =n, \quad n_{2}^{*}=n-(1-\varepsilon)(1-\alpha)\left(m_{2}-m_{1}\right) .
\end{array}
$$

The steady state associated with this CGP is locally stable.

Proof. Notice that equation (42) does not contain the variable $\chi$ and thus can be analysed independently. This equation gives $\dot{\kappa}=\kappa(1-\kappa)(1-\alpha)(1-\varepsilon)\left(m_{2}-m_{1}\right)$ which is the familiar logistic equation with two steady states, $\kappa^{*}=1$ and $\kappa^{* *}=0$. The first one is asymptotically stable, and the second one is asymptotically unstable. As $\kappa \rightarrow 1, \xi \rightarrow \gamma^{\frac{\varepsilon}{\varepsilon-1}}$ and $\chi \rightarrow \chi^{*}$. The CGP associated with the steady state $\left(1, \chi^{*}\right)$ is locally stable since, evaluated at this point, $\frac{\partial \widehat{\kappa}}{\partial \kappa}=(\alpha-1)(1-\varepsilon)\left(m_{2}-m_{1}\right)<0$ and $\frac{\partial \widehat{\chi}}{\partial \chi}=(\alpha-1)\left(\delta+n+m_{1}\right)<0$.

As in the AG model, growth is non-balanced with the two sectors growing permanently at different rates, the fractions of capital and labor allocated to the sector with high TFP growth asymptotically vanish, and structural change asymptotically ceases as the economy approaches the CGP. Nonetheless, this last feature is specific to our simplified version of the NG model. In their original framework, with several sectors producing only consumption goods and one sector producing consumption and capital goods, structural change among the consumption-producing sectors can still take place along the CGP.

\subsubsection{Case 3: Dynamics of the model of unequal sectoral capital-labor substi- tution}

Recall that this case arises when $\sigma_{2} \neq \sigma_{1}=1$. Furthermore, let $\varepsilon=1, \alpha_{2}=\alpha_{1}=\alpha$ and $M_{1}(t)=M_{2}(t)=M(t)$ which implies $m_{1}=m_{2}=m$. Combining (36), (24) and (26) we reach the following one-to-one relationship between $\chi$ and $\kappa$, 


$$
\chi=(\gamma(1-\alpha))^{\frac{\sigma_{2}}{\sigma_{2}-1}} \frac{(1-\kappa)^{\frac{1}{\sigma_{2}-1}}}{(\kappa-\alpha \gamma)(\kappa(1-\gamma(1-\alpha))-\alpha \gamma)^{\frac{1}{\sigma_{2}-1}}}
$$

where $\chi^{\prime}(\kappa)<0\left(\operatorname{resp} . \chi^{\prime}(\kappa)>0\right)$ for all $\kappa \in(\underline{\kappa}, 1)$ if $\sigma_{2}>1$ (resp. $\left.\sigma_{2}<1\right)$. Furthermore, it is worth noticing that when $\sigma_{2}>1, \chi(1)=0$ and $\lim _{\kappa \rightarrow \underline{\kappa}} \chi(\kappa)=\infty$, and when $\sigma_{2}<1$, $\chi(\underline{\kappa})=0$ and $\lim _{\kappa \rightarrow 1} \chi(\kappa)=\infty$.

Proposition 6. Under the stated assumptions, given the initial condition $\chi(0)=\chi_{0}$, the competitive equilibrium path satisfies the following differential equation:

$$
\dot{\kappa}=\frac{s A \pi(\kappa)-(\delta+m+n)}{H(\kappa)}
$$

where

$$
\begin{gathered}
A \equiv\left[\frac{1-\gamma}{\gamma}\right]^{\frac{(1-\gamma) \sigma_{2}}{\sigma_{2}-1}}(\gamma(1-\alpha))^{-\frac{(1-\alpha) \gamma}{\sigma_{2}-1}} \\
\pi(\kappa) \equiv \frac{\kappa^{\left(\sigma_{2}-\gamma\right) /\left(\sigma_{2}-1\right)}(\kappa(1-\gamma(1-\alpha))-\alpha \gamma)^{\frac{\gamma(1-\alpha)}{\sigma_{2}-1}}}{(1-\kappa)^{\frac{1-\alpha \gamma}{\sigma_{2}-1}}},
\end{gathered}
$$

and

$$
H(\kappa) \equiv-\left(\frac{1}{\sigma_{2}-1}\right)\left[\frac{(1-\gamma+\alpha \gamma)(\kappa-\alpha \gamma)+\sigma_{2}(\kappa(1-\gamma(1-\alpha))-\alpha \gamma)}{(\kappa-\alpha \gamma)(\kappa(1-\gamma(1-\alpha))-\alpha \gamma)}\right]
$$

where $H(\kappa)<0$ (resp. $H(\kappa)>0)$ for all $\kappa \in(\underline{\kappa}, 1)$ if $\sigma_{2}>1$ (resp. $\sigma_{2}<1$ ).

Proof. See Appendix A

Let's turn now to the characterization of the constant growth path.

Theorem 3. Under the stated assumptions, there exists a unique (non-trivial) CGP that satisfies

$$
\begin{aligned}
\pi\left(\kappa^{*}\right) & =\frac{\delta+m+n}{s A}, \quad \lambda^{*}=\frac{\gamma(1-\alpha) \kappa^{*}}{\kappa^{*}-\alpha \gamma}, \\
\chi^{*} & =(\gamma(1-\alpha))^{\frac{\sigma_{2}}{\sigma_{2}-1}} \frac{\left(1-\kappa^{*}\right)^{\frac{1}{\sigma_{2}-1}}}{\left(\kappa^{*}-\alpha \gamma\right)\left(\kappa^{*}(1-\gamma(1-\alpha))-\alpha \gamma\right)^{\frac{1}{\sigma_{2}-1}}} \\
g^{*} & =z^{*}=g_{1}^{*}=g_{2}^{*}=z_{1}^{*}=z_{2}^{*}=n_{1}^{*}=n_{2}^{*}=n+m .
\end{aligned}
$$

The steady state associated with this CGP is locally stable. 
Proof. Notice that (45) is an autonomous differential equation with a unique (nontrivial) steady state, $\kappa^{*}$. The CGP associated with this steady state is locally stable since, evaluated at that point, $\frac{\partial \dot{\kappa}}{\partial \kappa}=\frac{s A \pi^{\prime}\left(\kappa^{*}\right)}{H\left(\kappa^{*}\right)}<0$

This theorem has several interesting implications. First, since the sectoral TFP growth rates are identical, both sectors grow at the same rate along the CGP which, of course, is the same as the growth rate of the aggregate economy. Second, the steady state fractions of employment and capital are strictly positive in both sectors. As opposed to the previous models where the fractions of employment and capital in the sector that sheds resources asymptotically vanish, in this model both sectors reach the CGP with non-trivial shares of employment and capital. ${ }^{17}$ Third, it is worth noticing that along the CGP the capital-output ratio and the rental rate are constant, and as a result, so is the share of capital in national income, while the wage rate grows at the exogenous rate of TFP growth, $m$. Finally, as in the AG model, once the economy reaches the CGP the process of sectoral reallocation comes to an end.

\section{Optimal growth under unequal sectoral capital-labor substitution}

In this section we extend the previous analysis to the case of optimal saving. Let $C$ and $I$ denote consumption and gross investment respectively. Then

$$
\begin{gathered}
Y=C+I \\
\dot{K}=Y-C-\delta K=I-\delta K
\end{gathered}
$$

Let $c$ be consumption per unit of effective labour,

$$
c \equiv \frac{C}{M L}=\frac{C}{K}\left(\frac{K}{M L}\right)=\frac{C}{K} \chi
$$

Then

$$
\frac{I}{K}=\frac{Y}{K}-\frac{C}{K}=A \pi(\kappa)-\frac{c}{\chi}
$$

(where we have used (70)), and therefore the law of motion of capital per unit of effective labour becomes,

$$
\dot{\chi}=A \pi(\kappa) \chi-c-(\delta+m+n) \chi
$$

\footnotetext{
${ }^{17}$ Notice that when $m_{1}=m_{2}=0$ the AG model also reaches non-trivial steady-state allocations of capital and labor for both sectors. Nonetheless in this case growth eventually ceases. Similarly, non-trivial allocations along the CGP of the NP model occur when $m_{1}=m_{2}=m$, but in this case there is no structural change and the initial fractions of capital and labor allocated to each sector remain constant forever.
} 
Let the instantaneous utility function, $U(C / L)$, take the familiar CRRA specification where $1 /(1-\mu)>0$ is the intertemporal elasticity of substitution of consumption. Then the discounted life-time welfare of the representative household is

$$
\int_{0}^{\infty} e^{-\beta t} L U\left(\frac{C}{L}\right) d t=\int_{0}^{\infty} e^{-\beta t}\left(\frac{c^{\mu}}{\mu}\right) L M^{\mu} d t=\int_{0}^{\infty} e^{-(\beta-n-\mu m) t}\left(\frac{c^{\mu}}{\mu}\right) d t
$$

where $\beta$ is the rate of time preference and we have used the fact that population and TFP grow at the exogenous rates $n$ and $m$ respectively.

The solution to the optimal growth problem amounts to find the time path for $c$ that maximizes (50) subject to (49). Notice that given (44) $\kappa$ is a function of $\chi$ and we can define

$$
f(\chi) \equiv A \pi(\kappa(\chi)) \chi
$$

Therefore (49) becomes

$$
\dot{\chi}=f(\chi)-c-(\delta+m+n) \chi
$$

Thus, this optimization problem reduces to the standard optimal growth problem if $f(\chi)$ is a strictly concave and increasing function of $\chi$ with $f(0)=0$. Appendix B shows that $f(\chi)$ does indeed satisfy these properties.

Define

$$
\rho \equiv \beta-n-\mu m
$$

and assume that $\rho$ is positive. Let $\psi$ be the shadow price of $\chi$. The Hamiltonian for this problem is

$$
H=\frac{c^{\mu}}{\mu}+\psi[f(\chi)-c-(\delta+m+n) \chi]
$$

The necessary conditions are

$$
\begin{gathered}
c^{\mu-1}=\psi \\
\dot{\psi}=\psi\left[\rho+\delta+m+n-f^{\prime}(\chi)\right]
\end{gathered}
$$

together with the transversality condition, $\lim _{t \rightarrow \infty} \chi \psi \exp (-\rho t)=0$. The interpretation of these conditions is standard. Combining (53) and (54) we reach the familiar consumption Euler equation,

$$
\dot{c}=\frac{c}{1-\mu}\left[f^{\prime}(\chi)-\rho-\delta-m-n\right]
$$

that together with (52), the initial condition, $\chi(0)=\chi_{0}$, and the transversality condition fully describe the dynamic evolution of the economy. The steady state satisfies,

$$
\begin{gathered}
f^{\prime}\left(\chi^{*}\right)=\rho+\delta+m+n \\
c^{*}=f\left(\chi^{*}\right)-(\delta+m+n) \chi^{*}
\end{gathered}
$$

and the standard analysis applies. 


\section{Some suggestive evidence and additional issues}

Although the main focus of the paper is theoretical, in this section we provide some casual evidence that illustrates the relevance of the mechanism highlighted by the model and we discuss some further issues.

\subsection{Factor-intensity reversals}

If one assumes that sectoral production technologies are Cobb-Douglas or identical across sectors, as in AG and NP, then the sectoral ranking of factor-intensity is invariant with respect to the factor-price ratio; that is, if one sector is more capital-intensive than the other at a given set of factor prices it will remain so at any set of factor prices. The absence of factor-intensity reversals is a standard assumption in the trade literature (see, for instance, Samuelson's (1948, 1949) "Factor-Price Equalization Theorem"). Nonetheless, once one allows for different degrees of substitutability between factors, the possibility of a factorintensity reversal, a situation where the ordering of sectors by capital-intensity varies with the ratio of factor prices, reemerges.

Let $\omega \equiv \frac{w}{r+\delta}$ denote the wage-rental ratio. Assume $M_{1}=M_{2}=M$. Then (11) and (12) imply the following capital-labor ratios for the two sectors,

$$
\begin{aligned}
& k_{1} \equiv \frac{K_{1}}{L_{1}}=\left(\frac{\alpha}{1-\alpha}\right)^{\sigma_{1}} M^{1-\sigma_{1}} \omega^{\sigma_{1}} \\
& k_{2} \equiv \frac{K_{2}}{L_{2}}=\left(\frac{\alpha}{1-\alpha}\right)^{\sigma_{2}} M^{1-\sigma_{2}} \omega^{\sigma_{2}}
\end{aligned}
$$

Using (58) and (59) we can write the ratio of capital intensities as,

$$
\frac{k_{1}}{k_{2}}=Z \omega^{\sigma_{1}-\sigma_{2}}
$$

where $Z \equiv\left(\frac{1-\alpha}{\alpha} M\right)^{\sigma_{2}-\sigma_{1}}$

It is evident from (60) that a factor-intensity reversal might occur only if the degree of factor substitution varies across sectors. Furthermore, define the (time-varying) threshold factor-price ratio,

$$
\widetilde{\omega} \equiv Z^{\sigma_{2}-\sigma_{1}}=\frac{\alpha}{1-\alpha} M
$$

Then a factor-intensity reversal occurs as $\omega$ crosses the threshold $\widetilde{\omega}$. In particular, if $\sigma_{2}>\sigma_{1}$, we have

$$
k_{2}>k_{1} \Longleftrightarrow \omega>\widetilde{\omega}
$$


As the wage-rental ratio increases, the more flexible sector 2 increases its capital-labor ratio, becoming eventually, after the relative factor price crosses the threshold $\widetilde{\omega}$, more capitalintensive than the less flexible sector 1.

On the empirical front, the possibility of a factor-intensity reversal was the subject of an intense and inconclusive debate in the sixties. Comparing the rankings of capital-intensity for similar U.S. and Japanese industries, Minhas (1962) concluded that factor-intensity reversals were empirically relevant. By restricting the sample to a more homogeneous set of industries Ball (1966) concluded that the adjusted rankings were not so dissimilar as to validate the CES reversals result. Along similar lines, Hutcheson (1969) failed to reject the null hypothesis of a common elasticity of substitution across industries, concluding that Minhas' case against the standard assumption of non-reversal of factor-intensity was not founded. In contrast, Kurokawa (2010), in an attempt to explain the rising skill premium in the US, provides convincing evidence of a skill-intensity reversal between the US and Mexico.

Our model provides a framework to review this question in the context of a growing economy. The EU KLEMS database (O'Mahony and Timmer, 2009) provides capital-labor ratios for 32 industries, and Balistreri et al. (2002) report estimates at the industry-level for the elasticity of substitution using a 50 year panel compiled by the Bureau of Economic Analysis. Based on these estimates and on the levels of capital intensity in 1978 we choose a low elasticity sector, Rubber and Plastics, with estimates that range from 0.75 to 0.81 , and a high elasticity one, Electrical Equipment, with estimates that range from 2.9 to 3.7. Figure 2 reproduces the evolution of the capital-labor ratio for these two industries. ${ }^{18}$ At the beginning of our sample the less flexible industry, Rubber and Plastics, was more capital-intensive than Electrical Equipment. Between 1978 and 2007 the US aggregate capital-labor ratio increased by almost one half. As a result the more flexible industry, Electrical Equipment, increased its capital-labor ratio at a faster pace than the less flexible one. The reversal took place around 1990 and thereafter the more flexible industry became also more capital-intensive. Finally, when considering a long period of time one might wonder whether the observed change in the factor-intensity ratio, $k_{1} / k_{2}$, was driven by changes in the factor-price ratio or was simply the consequence of productivity growth. Fortunately, the EU KLEMS database

\footnotetext{
${ }^{18}$ Since Balistreri et al. (2002) use two-digit SIC industry codes to estimate their elasticities of substitution while our data for capital-labor ratios at the industry level uses the NACE classification codes, we need to map these two sources. We match "Rubber and miscellaneous plastic products" (SIC code 30) and "Rubber and Plastics" (NACE code 25). Unfortunately the EU KLEMS data does not include a direct match for "Electronic and other electric equipment" (SIC code 36). As a result we use the closest, although slightly broader, category of "Electrical and optical equipment" (NACE code 30-33).
} 
includes TFP estimates that suggest that TFP growth in Electrical Equipment outpaced by a factor of four that of Rubber and Plastics. Given that the estimate of the elasticity of the flexible sector exceeds unity we can discard differential productivity growth as a source for the observed reversal. ${ }^{19}$

\subsection{Structural change out of agriculture}

The process of economic development is always and everywhere characterized by substantial reallocations of resources out of agriculture. As a result of this process, the differences in sectoral structure between developed and developing countries are staggering. On one side, rich countries, such as the U.S., the U.K., or Belgium employ less than $3 \%$ of their labor force in agriculture, while, on the other side, poor countries, such as Nepal, Burundi, or Niger have employment shares in agriculture above 90\%. These differences in employment shares are compounded by important differences in labor productivity and capital intensity. As Restuccia et al (2008) and Chanda and Dalgaard (2008) report, the differences in agricultural labor productivity between rich and poor countries are twice as large than those in aggregate labor productivity. Mundlak (2000) finds that the distributions of the various measures of investment and capital show a much larger spread in agriculture than in the rest of the economy. Table 1 and Figures 3 and 4 use data for 50 countries collected by Crego et al. (2000) to illustrate the variation of sectoral capital-labor ratios across countries. In rich countries agriculture is more capital-intensive than the rest of the economy, while the reverse is true in poor economies. ${ }^{20}$ These differences in capital per worker across sectors and countries are stunning. In the 5 richest countries our sample capital per worker outside of agriculture is 14 times larger than in the 5 poorest countries, while in the agricultural sector capital per worker is more than 500 times larger. ${ }^{21}$

Given the important cross-country variation in wage-rental ratios, one may interpret the large sectoral variation in capital-labor ratios as the result of a relatively high elasticity of substitution between inputs in agriculture. This interpretation is consistent with the

\footnotetext{
${ }^{19}$ Allowing for sector-specific TFP we can write (60) as $\frac{k_{1}}{k_{2}}=\left(\frac{1-\alpha}{\alpha}\right)^{\sigma_{2}-\sigma_{1}} \frac{M_{1}^{\left(1-\sigma_{1}\right)}}{M_{2}^{\left(1-\sigma_{2}\right)}} \omega^{\sigma_{1}-\sigma_{2}}$. Assuming $\sigma_{2}>\sigma_{1}$ sector 2 would correspond to Electrical Equipment in our example. Then for a productivity-driven reversal, it is necessary that either $\sigma_{1}>1$ and $\hat{M}_{1}>\hat{M}_{2}$, or $\sigma_{2}<1$ and $\hat{M}_{2}>\hat{M}_{1}$. In view of the evidence discussed, neither condition seems to be satisfied.

${ }^{20}$ The correlation coefficient between capital per worker and income per worker is 0.95.

${ }^{21}$ The five richest countries in our sample are the US, Canada, Denmark, Norway and Sweden, while the five poorest ones are Tanzania, Malawi, Madagascar, Kenya and India. An example might help visualizing how these differences come about, for instance the Lexion 590R, the world's largest combine harvester, has the capacity to harvest 1,800 bushels of wheat per hour. This capacity is equivalent of 540 man-hours.
} 
estimates provided by Behrman (1972) who finds that the elasticity of substitution in agriculture, although small, is roughly three times larger than the one in services. ${ }^{22}$ Rosenweig (1988) implicitly acknowledges this substitution capability of agricultural production when arguing that obstacles to migration out of agriculture depress rural wages inducing farmers to substitute cheap labor for capital and intermediate inputs. Along similar lines Manuelli and Seshadri (2003) provide evidence on the impact of low labor costs on the slow rate of adoption of tractors in the U.S. agriculture between 1910 and 1940.

All this evidence suggests that the degree of flexibility in agricultural production may be important. Figures 5 and 6 report the evolution of the shares of employment and capital in agriculture for Chile and the Netherlands between 1967 and 1992. As opposed to previous models of structural change (either technology driven as in NP and AG, or preference driven as in Kongsamut et al. 2001), that imply that sectoral factor shares move in the same direction, with sectors either increasing or decreasing their shares of both inputs, our model provides a natural rationalization for the observed patterns where the agricultural sector's employment share decreases while its capital share increases ${ }^{23}$. This explanation combines the flexibility to substitute capital for labor in agricultural production with the secular increase in the relative price of labor. As the aggregate capital-labor ratio increases, the more flexible sector, agriculture, takes advantage of the change in relative prices substituting away from the relatively more expensive labor into the relatively cheaper capital. As a result the employment share in agriculture decreases while its share in the aggregate capital stock increases.

\subsection{The aggregate elasticity of substitution}

Evaluating the response of the economy-wide capital-labor ratio to changes in the factorprice ratio requires a measure of the degree of substitutability between capital and labor

\footnotetext{
${ }^{22}$ Services seem to be the relevant alternative since most of the sectoral reallocation takes place between these two sectors. For instance Kongsamut et al. (2001) report that the U.S. service employment share increased from $25 \%$ in 1869 to $75 \%$ in 1999, while the agricultural employment share decreased substantially over that period, from $50 \%$ to $2 \%$.

${ }^{23}$ Notice that the actual patterns of sectoral reallocation most likely reflect a combination of several mechanisms which include differences in income demand elasticities, differential productivity growth, differences in capital deepening and differences in the elasticities of substitution. Given that there is consensus on the fact that the income demand elasticity of agricultural goods is below one and that TFP growth in agriculture has outpaced that of the rest of the economy over the last half of the 20th century (see Alvarez-Cuadrado and Poschke, 2011), one can conclude that the first two mechanisms tend to reduce the fractions of labor and capital allocated to agriculture. Table 1 suggests that capital deepening is more important in agriculture than in the rest of the economy. As a result the third mechanism tends to increase the fraction of labor employed in the less flexible non-farm sector. Nonetheless, Dennis and Iscan (2009) find that the qualitative importance of capital deepening is second order when compared to the other two mechanisms.
} 
at the aggregate level. Acemoglu and Guerrieri (2008) address this question by evaluating the impact of capital accumulation on the capital share in national income. Since in their model, under the assumption that $\varepsilon<1$, they find a negative relationship between those two variables, they conclude that the economy-wide elasticity of substitution is less than one.

An attractive alternative way of evaluating this aggregate elasticity follows the dual approach developed in Jones (1965).

\section{Lemma 4.3.1}

The aggregate elasticity of substitution is a weighted average (i.e. the coefficients add up to one) of the three primary elasticities: the elasticity of substitution between the two intermediate inputs in the production of the final good, $\varepsilon$, and the two sectoral elasticities, $\sigma_{1}$ and $\sigma_{2}$ :

$$
\sigma=\gamma_{0} \varepsilon+\gamma_{1} \sigma_{1}+\gamma_{2} \sigma_{2}
$$

where

$$
\begin{gathered}
\gamma_{0} \equiv\left(\theta_{1 L}-\theta_{2 L}\right)(\lambda-\kappa) \\
\gamma_{1} \equiv \lambda \theta_{1 K}+\kappa \theta_{1 L} \\
\gamma_{2} \equiv(1-\lambda) \theta_{2 K}+(1-\kappa) \theta_{2 L}
\end{gathered}
$$

and $\theta_{i j}$ is the income share of factor $j$ in sector $i$.

\section{Proof: See Appendix A}

Although the primary elasticities are constant, in general the aggregate elasticity of substitution, $\sigma$, varies with the sectoral composition of output with three notable exceptions. First, when the three primary elasticities are equal, $\varepsilon=\sigma_{1}=\sigma_{2}$, the aggregate elasticity is constant and equal to the primary ones. For instance, reinterpreting the production function for final output as an utility aggregator, this happens when preferences and sectoral technologies are Cobb-Douglas as in Antras and Caballero (2009). Second, it is constant and equal to the elasticity of substitution in the final-good sector, $\varepsilon$, when one of the sectors uses only capital and the other only labor as in Ventura (1997). And finally it is also constant when the sectoral factor income shares and the sectoral elasticities are equal, i.e. $\theta_{1 K}=\theta_{2 K}$ and $\sigma_{1}=\sigma_{2}$. This last case includes the NP model where $\sigma_{1}=\sigma_{2}=1$ and $\theta_{1 K}=\theta_{2 K}=\alpha$. Intuitively, if factor income shares in both sectors are equal then the aggregate elasticity of substitution is independent of the elasticity of substitution of the final sector, $\gamma_{0}=0$. As a result, the aggregate elasticity reduces to a weighted average of the sectoral elasticities and it is constant when both sectoral elasticities coincide. 
The aggregate elasticity of substitution in the AG model, where $\sigma_{1}=\sigma_{2}=1$, is given by,

$$
\sigma=1+\left(\alpha_{2}-\alpha_{1}\right)(\lambda-\kappa)(\varepsilon-1)<1 \Longleftrightarrow \varepsilon<1
$$

In this case the aggregate elasticity, which varies with the process of structural change, exceeds unity if the elasticity of substitution between inputs in the final sector is above one. Notice that (61) reduces to a weighted average of the elasticity in the final sector, $\varepsilon$, and 1. As a result, whether the aggregate elasticity of substitution exceeds unity depends only on the elasticity of substitution in the final-good sector.

A final interesting case arises under the parameterization used in the model of unequal sectoral capital-labor substitution presented before where $\sigma_{2} \neq \sigma_{1}=\varepsilon=1$. In this case, the aggregate elasticity of substitution is given by,

$$
\sigma=\gamma_{0}+\gamma_{1}+\gamma_{2} \sigma_{2}<1 \Longleftrightarrow \sigma_{2}<1
$$

where $\sigma$ is a weighted average of 1 and one of the sectoral elasticities, $\sigma_{2}$. So necessarily $\sigma<1$ iff $\sigma_{2}<1$.

\subsection{A numerical example}

Since the actual patterns of structural change arise from a combination of several forces, of which differences in the sectoral elasticity of substitution is only one, our goal in this section is not to reproduce these patterns but rather to illustrate numerically some of the features of the model. In order to focus on the impact of differences in the elasticity of substitution we set both sectoral levels of TFP constant and equal to $1, M_{1}=M_{2}=1$. Furthermore, we normalize the labor force to 1 . For illustration purposes it proves convenient to track the evolution of key variables in terms of the wage-rental ratio, $\omega$. Notice that given $\omega,(58)$ and (59) determine the sectoral capital-labor ratios, $k_{i}(\omega)$ (where $i=1,2$ ). These ratios allow to calculate the sectoral factor income shares, given by $\theta_{i L}(\omega)=\frac{\omega}{k_{i}(\omega)+\omega}$, then $(4)$ and (5) determine the levels of per capita sectoral output, $f_{i}\left(k_{i}\right)$, and marginal products, $f_{i}^{\prime}\left(k_{i}\right)$. Combining these results with (11) determines the relative price of intermediate goods, $p(\omega) \equiv \frac{p_{1}}{p_{2}}=\frac{f_{2}^{\prime}\left(k_{2}\right)}{f_{1}^{\prime}\left(k_{1}\right)}$, and imposing the sectoral market clearing condition that equates relative supply, $p(\omega) \frac{Y_{1}}{Y_{2}}=p(\omega) \frac{\lambda}{(1-\lambda)} \frac{f_{2}\left(k_{2}\right)}{f_{1}\left(k_{1}\right)}$, to relative demand, given by (8), we recover the sectoral factor allocations, $\lambda(\omega)$ and $\kappa(\omega)$. Finally, the aggregate labor income share and capital-labor ratio are given by $\theta_{L}=\lambda \theta_{1 L}+(1-\lambda) \theta_{2 L}$ and $k=\frac{\lambda}{\kappa} k_{1}$, respectively. In order to explore the evolution of these variables we need to choose specific values for four parameters; 
$\gamma, \alpha, \sigma_{1}$ and $\sigma_{2}$. Consistent with our goal, illustration rather than realism, we assume that both intermediate inputs are equally important in the production of final output, $\gamma=1 / 2$, and we set the distributional share of capital at one third, $\alpha_{i}=1 / 3$ for $i=1,2$. Finally, we set the sectoral elasticities around the Cobb-Douglas threshold with $\sigma_{1}=0.8$ and $\sigma_{2}=1.2$ and therefore we refer to sector 2 as the flexible one. ${ }^{24}$

Figure 7 presents the results of these simulations. As the aggregate capital-labor ratio increases the rental rate falls relative to the wage and therefore the wage-rental ratio increases. The flexible sector is in a better position to take advantage of this decrease in the relative price of capital and, therefore, as capital accumulates the fraction of labor (capital) that it employs falls (increases). Notice that when labor is relatively abundant, (for instance $\omega=1$ ), the flexible sector employs roughly $52.5 \%$ of the labor force and only $44 \%$ of the capital stock but this situation is reversed as labor becomes relatively scarce. For instance as $\omega$ increases to 10 the flexible-sector share of labor falls by more than 6 percentage points while its share in the capital stock increases by almost 16 percentage points. As a result, the flexible sector is more labor-intensive (capital-intensive) when the aggregate capital-labor ratio is low (high) than the less flexible sector. This change in the ranking of capital intensities, a capital-intensity reversal, takes place when the aggregate capital-labor ratio is equal to 1 (see (60)). The third panel of Figure 6 reports the evolution of the labor income share. The relevant threshold to understand its evolution is given by the Cobb-Douglas case. When the elasticity of substitution equals one, factor income shares are independent of relative factor prices. In this case an increase in the relative factor price leads to a proportional decrease in the relative factor use, leaving the factor income shares unchanged. Now, since the elasticity of the flexible sector exceeds one its labor income share, $\theta_{2 L}$, falls with the wage-rental ratio since a decrease in relative price of capital leads to a more than proportional increase in the capital-labor ratio in this sector. The reverse is true in the other sector where the elasticity of substitution is less than one and therefore its labor income share, $\theta_{1 L}$, increases as capital accumulates. Given our parameter choices, i.e. the equal importance of both sectors for final production and the symmetry of the sectoral elasticities around one, this third panel resembles the data reported in Figure 1, with sectoral factor income shares moving in opposite directions while the aggregate labor income share is roughly constant.

\footnotetext{
${ }^{24} \mathrm{An}$ additional issue concerns the range of $\omega$ we consider in our numerical exercise. Figure 6 reports, in most cases, values in the range $\omega \in[2,20]$. To get a sense of the meaning of this range, consider a Solow model with $s=0.2, \delta=0.05, m=0.02$ and $n=0.01$, then if we move from $10 \%$ to $200 \%$ of the steady state capital stock the wage-rental rate ratio increases from 2.5 to 16 . If the same exercise is conducted assuming $m=n=0$ the wage-rental rate ratio increases from 2 to 17.5. Finally, a realistic parameterization of a multi-sector CES model requires the normalization concept introduced by Klump and de La Granville (2000).
} 
In general, aggregation dampens sectoral variation. In our example, sectoral variation (almost) perfectly cancels out at the aggregate level. The last panel of this figure presents the evolution of the relative price of the intermediate goods and of the aggregate elasticity of substitution. As the capital-labor ratio increases there is a tendency for the less flexible sector to increase its production at a slower pace than that of the more flexible one, since the elasticity of substitution in the final-good sector is one this relative scarcity of the less flexible intermediate input leads to a continuous increase in its relative price. Finally, we know from the previous analysis that the aggregate elasticity of substitution, $\sigma$, is simply a weighted average of the sectoral elasticities. Nonetheless the weight placed on the flexible sector increases as capital accumulates and therefore $\sigma$ also increases with development. This result is robust to alternative parameter configurations as long as the final sector is Cobb-Douglas. ${ }^{25}$ Along these lines, Duffy and Papageourgiou (2000) use World Bank data on capital stocks for 82 countries over 28 years to estimate the parameters of the CES. They use 4 subsamples and they find that the elasticity of substitution increases with development. In the view of our model, differences in sectoral elasticities coupled with the secular process of capital accumulation might lie behind this relationship between flexibility in production and the level of development.

\section{Conclusions}

We have developed a two-sector model where differences in the sectoral elasticity of substitution between capital and labor lead to a process of reallocation of resources. The mechanism behind this model is simple. As the wage-rental rate ratio changes, more flexible sectors -industries with a higher elasticity of substitution between capital and labor- are in a better position to take advantage of these changes than less flexible ones. As a result if the final-goods sector is Cobb-Douglas, as capital accumulates the flexible sector increases its share in the aggregate capital stock while it reduces its share in employment. Despite this process of structural change, the economy eventually reaches a constant growth path where the fractions of employment and capital in both sectors are positive and constant. Both the

\footnotetext{
${ }^{25}$ We have conducted several simulations with $\varepsilon \neq 1$. The results are qualitatively similar to the general patterns illustrated in figure 7. Nonetheless, two differences are worth mentioning. First, as the elasticity of substitution in the final-goods sector falls well below unity, for instance $\varepsilon<0.5$, the relationship between the AES and development is reversed. Second, for large values of the elasticity of substitution in the final sector, for instance $\varepsilon>2$, the relationship between sectoral factor allocations and relative factor prices becomes non-monotonic. As in the general case illustrated in figure 7, the fraction of capital allocated to the less flexible sector, $\kappa$, falls as the wage-rental rate ratio increases but, in this case, the fraction of labor allocated to this sector, $\lambda$, first increases and then decreases. The (high) flexibility to substitute intermediate inputs in the production of the final good lies behind this non-monotonic adjustment.
} 
transitional behavior and the steady state configuration of the unequal capital-labor substitution model are in sharp contrast with those of the existing models of structural change that exhibit a CGP, specifically the AG and NP models. ${ }^{26}$ In these models, a sector is either shedding both capital and labor or absorbing them and the sectoral shares of employment and capital asymptotically vanish for certain sectors.

Additionally, we show how our main results extend to a Ramsey environment, where saving is endogenous, and provide some suggestive evidence on the relevance of the mechanism stressed by this unequal capital-labor substitution model. Although our main focus was analytical we relied on a numerical example to illustrate some of the key features of the model.

The main contribution of this paper is theoretical and qualitative. A natural extension would be to explore the quantitative importance of the mechanism stressed by the model for the actual patterns of structural change. This will require a more realistic framework that incorporates other sources of sectoral reallocation that seem to be qualitatively important such as non-homothetic preferences and differential TFP growth. Furthermore, we could explore numerically whether structural change is consistent with quasi-balanced growth, i.e. whether changes in factor allocations are first-order (in magnitude) when changes in the great ratios are already of second-order.

Additionally, although there are several papers that estimate the aggregate elasticity of substitution, see Antras (2004) for a recent example, the empirical literature on the sectoral elasticities is sparse. Another natural extension of our line of work would pursue the estimation of these elasticities at different levels of aggregation. These sectoral estimates could be used to contrast some of the predictions of the model. In principle, existing datasets, such as the 35-industry KLEM developed by Dale W. Jorgenson and the EU-KLEMS gathered by the Groningen Growth and Development Center, provide the sectoral level data required for these estimations.

\footnotetext{
${ }^{26}$ In the model with non-homothetic preferences developed by Kongsamut et al (2001) exhibits similar patterns. In the limit one of the sector dissapears and along the CGP sectors grow at different rates.
} 


\section{Appendix A}

Proof of Proposition 1. Differentiating (16), treating $\lambda$ as a function of $\kappa$, we obtain

$$
\phi_{\kappa} d \kappa+\phi_{(k / M)} d(k / M)=0
$$

where

$$
\phi_{(k / M)}=-\frac{\kappa(1-\kappa)}{(k / M)}\left(\frac{1-\varepsilon}{\varepsilon}\right)\left(\alpha_{2}-\alpha_{1}\right)<0
$$

and

$$
\begin{aligned}
\phi_{\kappa} & =1+\kappa^{2} \frac{1-\gamma}{\gamma} \frac{\alpha_{2}}{\alpha_{1}}\left(\frac{1-\varepsilon}{\varepsilon}\right)\left(\frac{Y_{1}}{Y_{2}}\right)^{\frac{1-\varepsilon}{\varepsilon}}\left[\left(1-\alpha_{1}\right) \frac{\frac{\partial \lambda}{\partial \kappa}}{\lambda}+\left(1-\alpha_{2}\right) \frac{\frac{\partial \lambda}{\partial \kappa}}{(1-\lambda)}+\frac{\alpha_{1}}{\kappa}+\frac{\alpha_{2}}{(1-\kappa)}\right] \\
& =1+\left(\frac{1-\varepsilon}{\varepsilon}\right)\left[1+\left(\alpha_{2}-\alpha_{1}\right)(\kappa-\lambda)\right]>0 \text { since }\left|\left(\alpha_{2}-\alpha_{1}\right)(\kappa-\lambda)\right| \leq 1
\end{aligned}
$$

Therefore

$$
\frac{d \kappa}{d(k / M)}=-\frac{\phi_{(k / M)}}{\phi_{\kappa}}=-\frac{(1-\varepsilon)\left(\alpha_{2}-\alpha_{1}\right)(1-\kappa) \kappa}{\left[1+(1-\varepsilon)\left(\alpha_{2}-\alpha_{1}\right)(\kappa-\lambda)\right](k / M)}>0
$$

which is equivalent to (19).

Proof of Proposition 4. Log-differentiating (36) and using (3) we reach,

$$
\hat{\chi}=\hat{K}-n-m_{1}=s \frac{Y}{K}-\left(\delta+n+m_{1}\right)
$$

We must find an expression for $\frac{Y}{K}$ in terms of our two endogenous variables, $\chi$ and $\kappa$. Notice that (16) implies,

$$
\left(\frac{Y_{1}}{Y_{2}}\right)^{\frac{1-\varepsilon}{\varepsilon}}=\left(\frac{1-\kappa}{\kappa}\right)\left(\frac{\gamma}{1-\gamma}\right) \frac{\alpha_{1}}{\alpha_{2}}
$$

and dividing both sides of (1) by $Y_{1}$ we have,

$$
\frac{Y}{Y_{1}}=\left[\gamma+(1-\gamma)\left(\frac{Y_{2}}{Y_{1}}\right)^{\frac{\varepsilon-1}{\varepsilon}}\right]^{\frac{\varepsilon}{\varepsilon-1}}
$$

Combining these two expressions we reach,

$$
\frac{Y}{Y_{1}}=\gamma^{\frac{\varepsilon}{\varepsilon-1}}\left[1+\frac{\alpha_{1}}{\alpha_{2}}\left(\frac{1-\kappa}{\kappa}\right)\right]^{\frac{\varepsilon}{\varepsilon-1}} \equiv \eta
$$

Then, 


$$
Y=\eta Y_{1}=\eta\left(M_{1} \lambda L\right)^{1-\alpha_{1}}(\kappa K)^{\alpha_{1}}=\eta \lambda^{1-\alpha_{1}} \kappa^{\alpha_{1}} \chi^{\alpha_{1}-1} K
$$

which, when combined with (64), yields (38).

Now using equation (65) we reach

$$
\frac{\dot{\kappa}}{\kappa}=-\left(\frac{1-\varepsilon}{\varepsilon}\right)(1-\kappa)\left(\widehat{\frac{Y_{1}}{Y_{2}}}\right)
$$

Since $\frac{Y_{1}}{Y_{2}}=\lambda^{1-\alpha_{1}}(1-\lambda)^{-\left(1-\alpha_{2}\right)} \kappa^{\alpha_{1}}(1-\kappa)^{-\alpha_{2}}\left(\frac{L}{K}\right)^{\alpha_{2}-\alpha_{1}}\left(\frac{M_{1}}{M_{2}}\right)^{\alpha_{2}-\alpha_{1}}$, we obtain

$$
\left(\widetilde{Y_{1}} \frac{\partial \lambda}{Y_{2}}\right)=\left(1-\alpha_{1}\right) \frac{\frac{\partial \hat{\kappa}}{\lambda}}{\kappa}+\left(1-\alpha_{2}\right) \frac{\frac{\partial \lambda}{\partial \kappa}}{(1-\lambda)} \dot{\kappa}+\alpha_{1} \frac{\dot{\kappa}}{\kappa}+\alpha_{2} \frac{\dot{\kappa}}{(1-\kappa)}+\left(\alpha_{1}-\alpha_{2}\right)\left(\hat{\chi}+m_{2}\right)
$$

Substituting (68) into equation (67), using $\frac{\partial \lambda}{\partial \kappa}=\frac{\alpha_{1}}{\alpha_{2}} \frac{\left(1-\alpha_{2}\right)}{\left(1-\alpha_{1}\right)}\left(\frac{\lambda}{\kappa}\right)^{2}$ and $\frac{\kappa}{\lambda}=\left(\frac{1-\kappa}{1-\lambda}\right)\left(\frac{\alpha_{1}}{\alpha_{2}}\right)\left(\frac{1-\alpha_{2}}{1-\alpha_{1}}\right)$, we arrive at

$$
\dot{\kappa}=-\left(\frac{1-\varepsilon}{\varepsilon}\right)\left[\dot{\kappa}\left(1+\left(\alpha_{1}-\alpha_{2}\right)(\lambda-\kappa)\right)+\kappa(1-\kappa)\left(\alpha_{1}-\alpha_{2}\right)\left(\hat{\chi}+m_{2}\right)\right]
$$

which after some manipulation yields (39).

Proof of Theorem 1. Consider the curve $\widehat{\chi}=$ constant. Differentiating (38) (keeping $\widehat{\chi}=$ constant) we reach a positive relation between $\chi$ and $\kappa$ along the $\widehat{\chi}=$ constant schedule,

$$
\begin{aligned}
\frac{\partial \kappa}{\partial \chi} & =\frac{\left(1-\alpha_{1}\right)}{\chi\left(\frac{\frac{\partial \eta}{\partial \kappa}}{\eta}+\left(1-\alpha_{1}\right) \frac{\frac{\partial \lambda}{\partial \kappa}}{\lambda}+\frac{\alpha_{1}}{\kappa}\right)} \\
& =\frac{\kappa^{2}\left(1-\alpha_{1}\right)}{\chi\left(\frac{\varepsilon}{1-\varepsilon} \gamma \eta^{\frac{1-\varepsilon}{\varepsilon}} \frac{\alpha_{1}}{\alpha_{2}}+\left(1-\alpha_{2}\right) \frac{\alpha_{1}}{\alpha_{2}} \lambda+\alpha_{1} \kappa\right)}>0
\end{aligned}
$$

Thus this schedule is upward sloping in the space $(\chi, \kappa)$. In particular, the curve $\widehat{\chi}=0$ meets the line $\kappa=1$ at $\left(\frac{s \gamma^{\frac{\varepsilon}{\varepsilon-1}}}{\delta+n+m_{1}}\right)^{\frac{1}{1-\alpha_{1}}}$. Below this curve, we have $\hat{\chi}<0$. Setting (39) equal to zero requires $\kappa(1-\kappa)\left(\alpha_{2}-\alpha_{1}\right)\left(\hat{\chi}+m_{2}\right)=0$ which implies either $\kappa=1$ or $\hat{\chi} \neq-m_{2}$. The latter case cannot be a steady state. Therefore the only non-trivial steady state allocation of capital is $\kappa^{*}=1$, i.e. the relevant $\widehat{\kappa}=0$ schedule that determines the steady state is 
the horizontal line $\kappa=1$ in the space $(\chi, \kappa)$. Since the $\widehat{\chi}=$ constant schedule is strictly increasing in $\chi$ there exists a unique (non-trivial) steady state given by (40).

The growth rates of the asymptotically dominant sector (and therefore of the overall economy) are derived by combining the steady state solutions and the growth rates of the exogenous variables with (13), (36), and (66). The growth rates for sector 2 are given by the solution of the system of three equations on $g_{2}^{*}, z_{2}^{*}$ and $n_{2}^{*}$ that results from the logdifferentiation of (5), (11) and (12).

Now, we turn to the dynamic properties of this steady state. The linear approximation of (38) and (39) around (40) is given by,

$$
\left[\begin{array}{c}
\dot{\chi} \\
\dot{\kappa}
\end{array}\right]=\left[\begin{array}{ll}
\frac{\partial \dot{\chi}}{\partial \chi} & \frac{\partial \dot{\chi}}{\partial \kappa} \\
\frac{\partial \dot{\kappa}}{\partial \chi} & \frac{\partial \dot{\kappa}}{\partial \kappa}
\end{array}\right]_{\substack{\chi=\chi^{*} \\
\kappa=1}}\left[\begin{array}{c}
\chi-\chi^{*} \\
\kappa-1
\end{array}\right]
$$

with,

$$
\begin{aligned}
& \frac{\partial \dot{\chi}}{\partial \chi}=\alpha_{1} s \eta^{*}\left(\lambda^{*}\right)^{1-\alpha_{1}}\left(\kappa^{*}\right)^{\alpha_{1}}\left(\chi^{*}\right)^{\alpha_{1}-1}-\left(\delta+n+m_{1}\right)=\left(\alpha_{1}-1\right)\left(\delta+n+m_{1}\right)<0 \\
& \frac{\partial \dot{\chi}}{\partial \kappa}=s \eta^{*}\left(\lambda^{*}\right)^{1-\alpha_{1}}\left(\kappa^{*}\right)^{\alpha_{1}}\left(\chi^{*}\right)^{\alpha_{1}}\left(\frac{\frac{\partial \eta}{\partial \kappa}}{\eta^{*}}+\left(1-\alpha_{1}\right) \frac{\frac{\partial \lambda}{\partial \kappa}}{\lambda^{*}}+\frac{\alpha_{1}}{\kappa^{*}}\right)>0 \\
& \frac{\partial \dot{\kappa}}{\partial \chi}=\frac{\kappa^{*}\left(1-\kappa^{*}\right)\left(\alpha_{2}-\alpha_{1}\right)\left(s \eta^{*}\left(\alpha_{1}-1\right)\left(\lambda^{*}\right)^{1-\alpha_{1}}\left(\kappa^{*}\right)^{\alpha_{1}}\left(\chi^{*}\right)^{\alpha_{1}-2}\right)}{(1-\varepsilon)^{-1}+\left(\alpha_{2}-\alpha_{1}\right)\left(\lambda^{*}-\kappa^{*}\right)}=0 \\
& {\left[(1-2 \kappa)\left(\alpha_{2}-\alpha_{1}\right)\left(\hat{\chi}+m_{2}\right)+\kappa(1-\kappa)\left(\alpha_{2}-\alpha_{1}\right) \frac{\partial \hat{\chi}}{\partial \kappa}\right]} \\
& {\left[(1-\varepsilon)^{-1}+\left(\alpha_{2}-\alpha_{1}\right)(\lambda-\kappa)\right]-\kappa(1-\kappa)\left(\alpha_{2}-\alpha_{1}\right)^{2}\left(\hat{\chi}+m_{2}\right)\left(\frac{\frac{\partial \lambda}{\partial \kappa}}{\lambda}-1\right)} \\
& \frac{\partial \dot{\kappa}}{\partial \kappa}=\frac{}{\left[(1-\varepsilon)^{-1}+\left(\alpha_{2}-\alpha_{1}\right)(\lambda-\kappa)\right]^{2}} \\
& =\left(\alpha_{1}-\alpha_{2}\right) m_{2}(1-\varepsilon)<0
\end{aligned}
$$

It follows that the determinant of the Jacobian is positive and its trace negative. As a result the linear system has two negative eigenvalues and the steady state associated with this CGP is locally stable. ${ }^{27}$ Global analysis using arrows shows that paths converging to the steady state $\left(\chi^{*}, \kappa^{*}\right)$ can display non-monotone behavior.

\footnotetext{
${ }^{27}$ Notice that when $\alpha_{2}<\alpha_{1}$ then the determinant of the Jacobian would be negative and therefore the steady state exhibits the saddlepoint property. Nonetheless, the steady state under evaluation, $\kappa^{*}=\lambda^{*}=1$ was characterized under the assumption that sector 1 is the assymptotically dominant one. When one reverses labor intensities one changes the assymptotically dominant sector and therefore the stability properties of
} 
Proof of Proposition 5. Using (64) we need an expression for $\frac{Y}{K}$ in terms of our two endogenous variables. Under the NP restrictions, equation (1) can be written as,

$$
\begin{aligned}
Y & =\left[\gamma Y_{1}^{\frac{\varepsilon-1}{\varepsilon}}+(1-\gamma) Y_{2}^{\frac{\varepsilon-1}{\varepsilon}}\right]^{\frac{\varepsilon}{\varepsilon-1}} \\
& =\left[\gamma\left(\left(M_{1} \lambda L\right)^{1-\alpha}(\kappa K)^{\alpha}\right)^{\frac{\varepsilon-1}{\varepsilon}}+(1-\gamma)\left(\left(M_{2}(1-\lambda) L\right)^{1-\alpha}((1-\kappa) K)^{\alpha}\right)^{\frac{\varepsilon-1}{\varepsilon}}\right]^{\frac{\varepsilon}{\varepsilon-1}} \\
& =L^{1-\alpha} K^{\alpha}\left[\gamma\left(M_{1}^{1-\alpha} \kappa\right)^{\frac{\varepsilon-1}{\varepsilon}}+(1-\gamma)\left(M_{2}^{1-\alpha}(1-\kappa)\right)^{\frac{\varepsilon-1}{\varepsilon}}\right]^{\frac{\varepsilon}{\varepsilon-1}}
\end{aligned}
$$

where we have used the fact that the capital-labor ratios are identical across sectors, implying $\kappa=\lambda$. The preceding equation gives

$$
\begin{aligned}
\frac{Y}{K} & =\left(\frac{K}{L M_{1}}\right)^{\alpha-1} M_{1}^{\alpha-1}\left[\gamma\left(M_{1}^{1-\alpha} \kappa\right)^{\frac{\varepsilon-1}{\varepsilon}}+(1-\gamma)\left(M_{2}^{1-\alpha}(1-\kappa)\right)^{\frac{\varepsilon-1}{\varepsilon}}\right]^{\frac{\varepsilon}{\varepsilon-1}} \\
& =\chi^{\alpha-1}\left[\gamma \kappa^{\frac{\varepsilon-1}{\varepsilon}}+(1-\gamma)\left(\left(\frac{M_{2}}{M_{1}}\right)^{1-\alpha}(1-\kappa)\right)^{\frac{\varepsilon-1}{\varepsilon}}\right]^{\frac{\varepsilon}{\varepsilon-1}} \equiv \xi \chi^{\alpha-1}
\end{aligned}
$$

from which we obtain (41). The derivation of (42) is straight forward from (21).

Proof of Proposition 6. Using (36) we can rewrite (24),

$$
\frac{(1-\kappa)^{\frac{1}{\sigma_{2}}}}{\kappa} \frac{\lambda}{(1-\lambda)^{\frac{1}{\sigma_{2}}}}=\chi^{\frac{\sigma_{2}-1}{\sigma_{2}}}
$$

which, after using (26) to replace $\lambda$, becomes

$$
\chi=(\gamma(1-\alpha))^{\frac{\sigma_{2}}{\sigma_{2}-1}} \frac{(1-\kappa)^{\frac{1}{\sigma_{2}-1}}}{(\kappa-\alpha \gamma)(\kappa(1-\gamma(1-\alpha))-\alpha \gamma)^{\frac{1}{\sigma_{2}-1}}}
$$

where $\chi^{\prime}(\kappa)<0\left(\operatorname{resp} . \chi^{\prime}(\kappa)>0\right)$ for all $\kappa \in(\underline{\kappa}, 1)$ if $\sigma_{2}>1$ (resp. $\sigma_{2}<1$ ). Furthermore, it is worth noticing that when $\sigma_{2}>1, \chi(1)=0$ and $\lim _{\kappa \rightarrow \underline{\kappa}} \chi(\kappa)=\infty$, and when $\sigma_{2}<1$, $\chi(\underline{\kappa})=0$ and $\lim _{\kappa \rightarrow 1} \chi(\kappa)=\infty$.

Given (36) and $M_{1}=M_{2}$, the rate of change of the normalized capital stock is,

$$
\widehat{\chi}=\widehat{K}-\widehat{M}_{1}-\widehat{L}=s \frac{Y}{K}-\delta-m-n
$$

Since $\varepsilon=1$ and sector 1 has the Cobb-Douglas technology while sector 2 has the CES technology, the agregate output-capital ratio is given by

$$
\frac{Y}{K}=\left[\left(\lambda \chi^{-1}\right)^{1-\alpha}(\kappa)^{\alpha}\right]^{\gamma}\left[(1-\alpha)\left((1-\lambda) \chi^{-1}\right)^{\frac{\sigma_{2}-1}{\sigma_{2}}}+\alpha((1-\kappa))^{\frac{\sigma_{2}-1}{\sigma_{2}}}\right]^{\frac{(1-\gamma) \sigma_{2}}{\sigma_{2}-1}}
$$

the steady state characterized under the initial ranking of factor intensities. In fact, under our assumption $\alpha_{2}>\alpha_{1}$, there is a trivial steady state, $\kappa^{*}=\lambda^{*}=0$, that exhibits the saddle path property, since at that point $\frac{\partial \dot{\kappa}}{\partial \kappa}=\left(\alpha_{2}-\alpha_{1}\right) m_{2}(1-\varepsilon)>0$ while $\frac{\partial \dot{\chi}}{\partial \chi}<0$. 
which can be expressed using (23), (25), (26), and (44) as

$$
\frac{Y}{K}=A \pi(\kappa)
$$

where $A$ and $\pi(\kappa)$ are defined by (46) and (47) respectively. Notice that when $\sigma_{2}>1$ ( respectively, $\gamma<\sigma_{2}<1$ ), $\pi(\kappa)$ is an increasing resp. decreasing) function defined over the interval $[\underline{\kappa}, 1]$, with $\pi(\underline{\kappa})=0$ (resp. $\pi(\kappa)=\infty)$ and $\lim _{\kappa \rightarrow 1} \pi(\kappa)=\infty(\operatorname{resp} . \pi(1)=0)$.

Therefore

$$
\widehat{\chi}=s A \pi(\kappa)-(\delta+m+n)
$$

Finally log-differentiating (44)

$$
\widehat{\chi}=-H(\kappa) \dot{\kappa}
$$

where $H(\kappa)$ is defined by

$$
H(\kappa) \equiv-\left(\frac{1}{\sigma_{2}-1}\right) \frac{1}{1-\kappa}-\frac{\left(\sigma_{2}-1\right)}{(\kappa-\alpha \gamma)\left(\sigma_{2}-1\right)}-\left(\frac{1}{\sigma_{2}-1}\right) \frac{1-\gamma(1-\alpha)}{\kappa(1-\gamma(1-\alpha))-\alpha \gamma}
$$

Then

$$
H(\kappa)=-\left(\frac{1}{\sigma_{2}-1}\right)\left[\frac{1}{1-\kappa}+\frac{\sigma_{2}-1}{(\kappa-\alpha \gamma)}+\frac{1-\gamma(1-\alpha)}{\kappa(1-\gamma(1-\alpha))-\alpha \gamma}\right]
$$

where the terms inside [..] is equal to

$$
\frac{(1-\gamma+\alpha \gamma)(1-\kappa)(\kappa-\alpha \gamma)+\sigma_{2}(1-\kappa)(\kappa(1-\gamma(1-\alpha))-\alpha \gamma)}{(1-\kappa)(\kappa-\alpha \gamma)(\kappa(1-\gamma(1-\alpha))-\alpha \gamma)}
$$

i.e.

$$
\frac{(1-\gamma+\alpha \gamma)(\kappa-\alpha \gamma)+\sigma_{2}(\kappa(1-\gamma(1-\alpha))-\alpha \gamma)}{(\kappa-\alpha \gamma)(\kappa(1-\gamma(1-\alpha))-\alpha \gamma)}
$$

which is positive for all $\kappa \in[\underline{\kappa}, 1]$.

Combining (72) with (71) yields (45).

Proof of Lemma 4.3.1. This proof follows Jones (1965) and Miyagiwa and Papageourgiou (2007). The dual relationship between sectoral prices and input prices and factor endowments and sectoral outputs are given by,

$$
\begin{gathered}
C_{1}(w, r) \equiv \frac{L_{1}}{Y_{1}} w+\frac{K_{1}}{Y_{1}} r=p_{1} \\
C_{2}(w, r) \equiv \frac{L_{2}}{Y_{2}} w+\frac{K_{2}}{Y_{2}} r=p_{2} \\
Y_{1} C_{1 w}+Y_{2} C_{2 w}=L \\
Y_{1} C_{1 r}+Y_{2} C_{2 r}=K
\end{gathered}
$$


where $C_{i}(w, r)$ is the unit cost function for good $i=1,2$ and $C_{i j}$ are its partial derivatives with respect to each factor price $j=w, r$.

Differentiating the previous expressions we reach the following relationships,

$$
\begin{gathered}
\frac{w L_{1}}{p_{1} Y_{1}} \hat{w}+\frac{r K_{1}}{p_{1} Y_{1}} \hat{r}=\theta_{1 L} \hat{w}+\theta_{1 K} \hat{r}=\widehat{p}_{1} \\
\frac{w L_{2}}{p_{2} Y_{2}} \hat{w}+\frac{r K_{2}}{p_{2} Y_{2}} \hat{r}=\theta_{2 L} \hat{w}+\theta_{2 K} \hat{r}=\widehat{p}_{2} \\
\lambda\left(\hat{Y}_{1}+\widehat{C}_{1 w}\right)+(1-\lambda)\left(\hat{Y}_{2}+\widehat{C}_{2 w}\right)=\hat{L} \\
\kappa\left(\hat{Y}_{1}+\widehat{C}_{1 r}\right)+(1-\kappa)\left(\hat{Y}_{2}+\widehat{C}_{2 r}\right)=\hat{K}
\end{gathered}
$$

where $\theta_{i l}$ are the factor income shares, $l=L, K$, in each industry.

Subtracting (77) and (78), and using the fact that the sectoral production functions are homogeneous of degree one we reach,

$$
\left(\theta_{1 L}-\theta_{2 L}\right)(\hat{w}-\hat{r})=\left(\theta_{2 K}-\theta_{1 K}\right)(\hat{w}-\hat{r})=\widehat{p}_{1}-\widehat{p}_{2}
$$

Using the definition of the sector-specific elasticity of substitution, $\sigma_{i} \equiv \frac{C_{i} C_{i w r}}{C_{i w} C_{i r}}$, since we can express the factor income shares as $\theta_{i l}=\frac{l C_{i r}}{d_{i}}$, we reach the following rates of change of partial derivatives of the unit cost functions,

$$
\begin{gathered}
\widehat{C}_{i w}=\frac{C_{i w w} d w+C_{i w r} d r}{C_{i w}}=\frac{-C_{i w r} \frac{r}{w} d w+C_{i w r} d r}{C_{i w}}= \\
-\frac{\left(C_{i w r} r \hat{w}-C_{i w r} d r\right)}{C_{i w}}=-\frac{C_{i w r} r}{C_{i w}}(\hat{w}-\hat{r})=-\frac{C_{i} C_{i w r}}{C_{i w} C_{i r}} \frac{r C_{i r}}{C_{i}}(\hat{w}-\hat{r})
\end{gathered}
$$

where the second equality uses the fact that $C_{i w}(w, r)$ is homogeneous of degree 0 . As a result

$$
\begin{aligned}
\widehat{C}_{i w} & =-\sigma_{i} \theta_{i K}(\hat{w}-\hat{r}) \\
\widehat{C}_{i r} & =\sigma_{i} \theta_{i L}(\hat{w}-\hat{r})
\end{aligned}
$$

Replacing (82) and (83) in (79) and (80) and subtracting them we reach,

$$
(\lambda-\kappa)\left(\hat{Y}_{1}-\hat{Y}_{2}\right)=(\hat{L}-\hat{K})+\Theta(\hat{w}-\hat{r})
$$

where $\Theta \equiv \lambda \sigma_{1} \theta_{1 K}+(1-\lambda) \sigma_{2} \theta_{2 K}+\kappa \sigma_{1} \theta_{1 L}+(1-\kappa) \sigma_{2} \theta_{2 L}$.

Finally, we use (7) to reach 


$$
\hat{Y}_{1}-\hat{Y}_{2}=-\varepsilon\left(\widehat{p}_{1}-\widehat{p}_{2}\right)
$$

Since the aggregate elasticity of substitution is defined as $\sigma \equiv-\frac{(\hat{L}-\hat{K})}{(\hat{w}-\hat{r})}$ we combine (81) and (84) in (85) to reach (61). 


\section{Appendix B}

In order to show that $f(\chi)$ is a strictly concave and increasing function of $\chi$ with $f(0)=$ 0 , we develop below a general framework for the analysis of the aggregate production using properties of the sectoral production functions.

Assumption P1: There are two intermediate goods, produced by capital and labor under concave, twice-continuously differentiable production functions

$$
Y_{i}=g^{i}\left(K_{i}, L_{i}\right)
$$

with the following properties: (i) $g^{i}\left(0, L_{i}\right)=0=g^{i}\left(K_{i}, 0\right)$, (ii) $g^{i}\left(\mu K_{i}, \mu L_{i}\right)=\mu g^{i}\left(K_{i}, L_{i}\right)$ for all $\mu>0$,(iii) $g^{i}$ is strictly increasing and strictly concave in each argument, i.e.

$$
g_{j}^{i}>0 \text { and } g_{j j}^{i}<0 \text { for each input } j
$$

(iv) the marginal product of an input tends to infinity as the input tends to zero

$$
\begin{aligned}
& \lim _{K_{i} \rightarrow 0} g_{1}^{i}\left(K_{i}, L_{i}\right)=\infty \text { for all } L_{i}>0 \\
& \lim _{L_{i} \rightarrow 0} g_{2}^{i}\left(K_{i}, L_{i}\right)=\infty \text { for all } K_{i}>0
\end{aligned}
$$

and $(\mathrm{v}) g^{i}$ is strictly quasi-concave, in particular, the following sufficient condition for a strictly quasi-concave function is met:

$$
\operatorname{det}\left[\begin{array}{ccc}
0 & g_{1}^{i} & g_{2}^{i} \\
g_{1}^{i} & g_{11}^{i} & g_{12}^{i} \\
g_{2}^{i} & g_{21}^{i} & g_{22}^{i}
\end{array}\right]>0
$$

Assumption P2: The production function of the final good is a concave, twice-continuously differentiable production function

$$
Y=H\left(Y_{1}, Y_{2}\right)
$$

where (i) $H\left(0, Y_{2}\right)=0=H\left(Y_{1}, 0\right)$, (ii) $H\left(\mu Y_{1}, \mu Y_{2}\right)=\mu H\left(Y_{1}, Y_{2}\right)$ for all $\mu>0$, (iii) $H$ is strictly increasing and strictly concave in each argument, i.e.

$$
H_{j} \equiv \frac{\partial H}{\partial Y_{j}}>0 \text { and } H_{j j}<0 \text { for } j=Y_{1} \text { or } Y_{2}
$$

(iv) the marginal product of an input $Y_{i}$ tends to infinity as the input tends to zero

$$
\begin{aligned}
& \lim _{Y_{1} \rightarrow 0} H_{1}\left(Y_{1}, Y_{2}\right)=\infty \text { for all } Y_{2}>0 \\
& \lim _{Y_{2 i} \rightarrow 0} H_{2}\left(Y_{1}, Y_{2}\right)=\infty \text { for all } Y_{1}>0
\end{aligned}
$$


and (v) $H$ is strictly quasi-concave, in particular, the following sufficient condition for a strictly quasi-concave function is met:

$$
\operatorname{det}\left[\begin{array}{ccc}
0 & H_{1} & H_{2} \\
H_{1} & H_{11} & H_{12} \\
H_{2} & H_{21} & H_{22}
\end{array}\right]>0
$$

From the above assumptions, we can obtain useful information about the aggregate production function, $Y=F(K, L)$ which we will define below.

Let us define the function

$$
h\left(K_{1}, L_{1}, K_{2}, L_{2}\right) \equiv H\left(g^{1}\left(K_{1}, L_{1}\right), g^{2}\left(K_{2}, L_{2}\right)\right)
$$

and use the following notations

$$
h_{1}=\frac{\partial h}{\partial K_{1}}, h_{2}=\frac{\partial h}{\partial L_{1}}, h_{3}=\frac{\partial h}{\partial K_{2}}, h_{4}=\frac{\partial h}{\partial L_{2}}, h_{11}=\frac{\partial^{2} h}{\left(\partial K_{1}\right)^{2}}, \ldots
$$

Note that

$$
h_{1}=H_{1} g_{1}^{1}, h_{2}=H_{1} g_{2}^{1}, h_{3}=H_{2} g_{1}^{2}, h_{4}=H_{2} g_{2}^{2}, \ldots
$$

Lemma A1: The function $h\left(K_{1}, L_{1}, K_{2}, L_{2}\right)$ is

(i) homogeneous of degree one in $\left(K_{1}, L_{1}, K_{2}, L_{2}\right)$,

(ii) concave in $\left(K_{1}, L_{1}, K_{2}, L_{2}\right)$,

(iii) strictly increasing in each argument,

(iv) strictly concave in each argument,

(v) strictly quasi-concave.

\section{Proof:}

Part (i): Straight forward from homogeneity of degree one of $g^{1}, g^{2}$ and $H$.

Part (ii): For simplicity of notation in the following proof, define the vectors

$$
\mathbf{u} \equiv\left(K_{1}, L_{1}\right) \in \mathbb{R}_{+}^{2}, \mathbf{v} \equiv\left(K_{2}, L_{2}\right) \in \mathbb{R}_{+}^{2}, \text { and } \mathbf{x} \equiv(\mathbf{u}, \mathbf{v}) \in \mathbb{R}_{+}^{4}
$$

Take any pair $\mathbf{x}, \mathbf{x}^{\prime} \in \mathbb{R}_{+}^{4}$, such that $\mathbf{x} \equiv(\mathbf{u}, \mathbf{v}) \neq \mathbf{x}^{\prime} \equiv\left(\mathbf{u}^{\prime}, \mathbf{v}^{\prime}\right)$, and let $\mathbf{x}_{\alpha} \equiv \alpha \mathbf{x}+(1-\alpha) \mathbf{x}^{\prime}$ where $\alpha \in(0,1)$, we must show that $h\left(\mathbf{x}_{\alpha}\right) \geq \alpha h(\mathbf{x})+(1-\alpha) h\left(\mathbf{x}^{\prime}\right)$. Now

$$
\mathbf{x}_{\alpha}=\alpha(\mathbf{u}, \mathbf{v})+(1-\alpha)\left(\mathbf{u}^{\prime}, \mathbf{v}^{\prime}\right) \equiv\left(\mathbf{u}_{\alpha}, \mathbf{v}_{\alpha}\right)
$$

where $\mathbf{u}_{\alpha} \equiv \alpha \mathbf{u}+(1-\alpha) \mathbf{u}^{\prime}$ and $\mathbf{v}_{\alpha} \equiv \alpha \mathbf{v}+(1-\alpha) \mathbf{v}^{\prime}$. Then

$$
h\left(\mathbf{x}_{\alpha}\right) \equiv H\left(g^{1}\left(\mathbf{u}_{\alpha}\right), g^{2}\left(\mathbf{v}_{\alpha}\right)\right)
$$




$$
\geq H\left(\alpha g^{1}(\mathbf{u})+(1-\alpha) g^{1}\left(\mathbf{u}^{\prime}\right), \alpha g^{2}(\mathbf{v})+(1-\alpha) g^{2}\left(\mathbf{v}^{\prime}\right)\right)
$$

because $g^{i}$ is concave and $H$ is increasing in $Y_{1}, Y_{2}$,

$$
\geq \alpha H\left(g^{1}(\mathbf{u}), g^{2}(\mathbf{v})\right)+(1-\alpha) H\left(g^{1}\left(\mathbf{u}^{\prime}\right), g^{2}\left(\mathbf{v}^{\prime}\right)\right)
$$

because $H$ is concave in $Y_{1}, Y_{2}$,

$$
\equiv \alpha h(\mathbf{u}, \mathbf{v})+(1-\alpha) h\left(\mathbf{u}^{\prime}, \mathbf{v}^{\prime}\right) \equiv \alpha h(\mathbf{x})+(1-\alpha) h\left(\mathbf{x}^{\prime}\right)
$$

Parts (iii) and (iv): Straightforward.

Part (v): We consider the following bordered Hessian

$$
\left[\begin{array}{ccccc}
0 & h_{1} & h_{2} & h_{3} & h_{4} \\
h_{1} & h_{11} & h_{12} & h_{13} & h_{14} \\
h_{2} & h_{21} & h_{22} & h_{23} & h_{24} \\
h_{3} & h_{31} & h_{32} & h_{33} & h_{34} \\
h_{4} & h_{41} & h_{42} & h_{43} & h_{44}
\end{array}\right]
$$

Note that a set of sufficient conditions for $H$ to be strictly quasi-concave is that the sign of $(-1)^{n} \operatorname{det} B_{n}>0$ for $n=1,2,3,4$, where $B_{n}$ is of order $(n+1) \times(n+1)$ (see e.g. Takayama (1985)). Making use of the fact that $H_{i}>0$ and $H_{i i}<0$, it is routine to evaluate the sign of the above determinants

Next, we define the following aggregate production function $F: \mathbb{R}_{+}^{2} \rightarrow \mathbb{R}_{+}$where

$$
F(K, L) \equiv \sup \left\{Y \in \mathbb{R}_{+}^{2} \mid Y \leq h\left(K_{1}, L_{1}, K_{2}, L_{2}\right), K_{1}+K_{2} \leq K \text { and } L_{1}+L_{2} \leq L\right\}
$$

Lemma A2: The function $F(K, L)$ is

(i) homogeneous of degree one in $(K, L)$

(ii) concave in $(K, L)$, hence $F_{K K} \leq 0$ and $F_{L L} \leq 0$

(iii) strictly increasing in each argument

(iv) strictly concave in each argument

\section{Proof:}

Part (i): Given $(K, L)>(0,0)$, let $\mathbf{x}^{*} \equiv\left(K_{1}^{*}, L_{1}^{*}, K_{2}^{*}, L_{2}^{*}\right)$ be the solution of the problem

$$
\max h\left(K_{1}, L_{1}, K_{2}, L_{2}\right) \text { s.t. } K_{1}+K_{2} \leq K \text { and } L_{1}+L_{2} \leq L \text {. }
$$

and let

$$
Y^{*}=h\left(K_{1}^{*}, L_{1}^{*}, K_{2}^{*}, L_{2}^{*}\right) \equiv h\left(\mathbf{x}^{*}\right)
$$

Let $\mu>0$ be any positive real number. Consider the problem

$$
\max h\left(K_{1}, L_{1}, K_{2}, L_{2}\right) \text { s.t. } K_{1}+K_{2} \leq \mu K \text { and } L_{1}+L_{2} \leq \mu L \text {. }
$$


Since $h($.$) is homogeneous of degree 1$ (by Lemma A1), it follows that $\left(\mu K_{1}^{*}, \mu L_{1}^{*}, \mu K_{2}^{*}, \mu L_{2}^{*}\right)$ solves this problem, and $Y^{* *} \equiv h\left(\mu K_{1}^{*}, \mu L_{1}^{*}, \mu K_{2}^{*}, \mu L_{2}^{*}\right)=\mu h\left(K_{1}^{*}, L_{1}^{*}, K_{2}^{*}, L_{2}^{*}\right)=\mu Y^{*}$. This proves that $F(K, L)$ is homogeneous of degree one in $(K, L)$.

Part (ii): Consider any pair of endowment vectors $\left(K^{\prime}, L^{\prime}\right)$ and $\left(K^{\prime \prime}, L^{\prime \prime}\right)$. Let $\mathbf{x}^{\prime} \in \mathbb{R}_{+}^{4}$ be the solution when $(K, L)=\left(K^{\prime}, L^{\prime}\right)$ and $\mathbf{x}^{\prime \prime} \in \mathbb{R}_{+}^{4}$ be the solution when $(K, L)=\left(K^{\prime \prime}, L^{\prime \prime}\right)$. For any $\alpha \in(0,1)$, let

$$
\left(K_{\alpha}, L_{\alpha}\right) \equiv \alpha\left(K^{\prime}, L^{\prime}\right)+(1-\alpha)\left(K^{\prime}, L^{\prime}\right)
$$

Clearly, when $(K, L)=\left(K_{\alpha}, L_{\alpha}\right)$, a feasible output is $h\left(\mathbf{x}_{\alpha}\right)$ where $\mathbf{x}_{\alpha} \equiv \alpha \mathbf{x}^{\prime}+(1-\alpha) \mathbf{x}^{\prime \prime}$, and since $h$ is concave,

$$
h\left(\mathbf{x}_{\alpha}\right) \geq \alpha h\left(\mathbf{x}^{\prime}\right)+(1-\alpha) h\left(\mathbf{x}^{\prime}\right) .
$$

Thus, by definition,

$$
F\left(K_{\alpha}, L_{\alpha}\right) \geq h\left(\mathbf{x}_{\alpha}\right) \geq \alpha h(\mathbf{x})+(1-\alpha) h\left(\mathbf{x}^{\prime}\right)=\alpha F\left(K^{\prime}, L^{\prime}\right)+(1-\alpha) F\left(K^{\prime \prime}, L^{\prime \prime}\right)
$$

It follows that $F($.$) is concave in (K, L)$. This implies that $F_{K K} \leq 0$ and $F_{L L} \leq 0$.

Part (iii): Since $h$ is an increasing function and any increase in $K$ allows both $K_{1}$ and $K_{2}$ to be increased, thus aggregate output $Y$ is increasing in the aggregate capital stock. So $\partial Y / \partial K>0$ and similarly, $\partial Y / \partial L>0$.

Part (iv): Set up the Lagrangian

$$
\mathcal{L}=h\left(K_{1}, L_{1}, K_{2}, L_{2}\right)+\lambda_{1}\left(K-K_{1}-K_{2}\right)+\lambda_{2}\left(L-L_{1}-L_{2}\right)
$$

By the envelope theorem,

$$
\frac{\partial Y}{\partial K}=\frac{\partial \mathcal{L}}{\partial K}=\lambda_{1}
$$

Using the first order conditions for problem (86) it is a standard, although tedious, exercise on comparative statics to show that $\frac{\partial^{2} Y}{\partial K^{2}}=\frac{\partial \lambda_{1}}{\partial K}<0$

Notice that it is trivial to extend the previous analysis to allow for Harrod neutral technological progress.

Now, given (36) and Lemma A2(i) we define aggregate output per unit of effective labor as

$$
\frac{Y}{M L}=F\left(\frac{K}{M L}, 1\right) \equiv f(\chi)
$$

Lemma 1: $f(\chi)$ is strictly increasing.

Proof: From (44) we know that there is a monotone decreasing (increasing) relationship between $\kappa$ and $\chi$ if $\sigma_{2}>1\left(\sigma_{2}<1\right)$. So we need to show that $R(\kappa) \chi(\kappa)$ is decreasing (increasing) in $\kappa$ if $\sigma_{2}>1\left(\sigma_{2}<1\right)$. 
Combining (47) and (44) we have that,

$$
\pi(\kappa(\chi)) \chi=\frac{B(1-\kappa)^{\frac{\alpha \gamma}{\sigma_{2}-1}} \kappa^{\left(\sigma_{2}-\gamma\right) /\left(\sigma_{2}-1\right)}}{(\kappa-\alpha \gamma)(\kappa(1-\gamma(1-\alpha))-\alpha \gamma)^{\frac{1-\gamma(1-\alpha)}{\sigma_{2}-1}}} \equiv h(\kappa)>0 \text { for } \kappa \in(\underline{\kappa}, 1)
$$

where $B \equiv(\gamma(1-\alpha))^{\frac{\sigma_{2}}{\sigma_{2}-1}}$.

Then we can express (87) as

$$
f(\chi)=A h(\kappa(\chi))
$$

and therefore

$$
f^{\prime}(\chi)=A h^{\prime}(\kappa) \frac{d \kappa}{d \chi}=A h(\kappa) \frac{d \ln h}{d \kappa} \frac{d \kappa}{d \chi}=\frac{A h(\kappa)}{\left(\frac{d \chi}{d \kappa}\right)} \frac{d \ln h}{d \kappa}=A \frac{h(\kappa)}{\chi} \frac{\frac{d \ln h}{d \kappa}}{\frac{d \ln \chi}{d \kappa}}=A \pi(\kappa) \frac{\frac{d \ln h}{d \kappa}}{\frac{d \ln \chi}{d \kappa}}
$$

Log-differentiating (88) we reach

$$
\frac{d \ln h}{d \kappa}=-\frac{\alpha \gamma}{\left(\sigma_{2}-1\right)(1-\kappa)}-\frac{[1-\gamma(1-\alpha)]^{2}}{\left(\sigma_{2}-1\right)(\kappa(1-\gamma(1-\alpha))-\alpha \gamma)}+\frac{\sigma_{2}-\gamma}{\left(\sigma_{2}-1\right) \kappa}-\frac{1}{\kappa-\alpha \gamma}
$$

that after re-arranging becomes

$$
\frac{d \ln h}{d \kappa}=\frac{1}{\left(1-\sigma_{2}\right) D(\kappa)}\left(\phi(\kappa)+\alpha \gamma \sigma_{2}(1-\kappa)(\kappa(1-\gamma(1-\alpha))-\alpha \gamma)\right)
$$

where

$$
\phi(\kappa) \equiv \alpha \gamma\left[(1-\gamma+\alpha \gamma) \kappa^{2}-2 \alpha \kappa \gamma+\alpha \gamma^{2}\right]
$$

and

$$
D(\kappa) \equiv(1-\kappa) \kappa(\kappa-\alpha \gamma)(\kappa(1-(1-\alpha) \gamma)-\alpha \gamma)>0 \text { for all } \kappa \in(\underline{\kappa}, 1)
$$

Notice that $\phi($.$) is a strictly convex function that attains a minimum at \kappa=\frac{\alpha \gamma}{1-\gamma+\alpha \gamma}=\underline{\kappa}$. Furthermore evaluated at $\underline{\kappa}$ we find $\phi(\underline{\kappa})>0$, so it follows that $\phi(\kappa) \geq \phi(\underline{\kappa})>0$ for all $\kappa \in[\underline{\kappa}, 1]$. Therefore, we conclude that $\operatorname{sign}\left(\frac{d \ln h}{d \kappa}\right)=\operatorname{sign}\left(1-\sigma_{2}\right)$

Lemma 2: $f(\chi)$ is strictly concave.

Proof: Straight forward from Lemma A2.

Lemma 3: The function $f(\chi)$ has the following properties: $f(0)=0$ and $f(\infty)=\infty$.

Proof: Consider the case $\sigma_{2}>1$. As $\chi \rightarrow 0, \kappa(\chi) \rightarrow 1$, and since $\lim _{\kappa \rightarrow 1} h(\kappa)=0$, we have $f(0)=0$. As $\chi \rightarrow \infty, \kappa(\chi) \rightarrow \underline{\kappa}$ and since $\lim _{\kappa \rightarrow \underline{\kappa}} h(\kappa)=\infty$, we have $f(\infty)=\infty$. A similar reasoning can be applied when $\sigma_{2}<1$ 


\section{Appendix C (not intended for publication)}

In this appendix we provide additional details on some of the derivations.

\section{Section 2.3.3.}

\section{Proposition 3}

Combining (23) and (25) we obtain

$$
\kappa=(1-\kappa)^{1 / \sigma_{2}}\left(\frac{\gamma}{1-\gamma}\right)\left[(1-\alpha)(1-\lambda)^{\frac{\sigma_{2}-1}{\sigma_{2}}}\left(\frac{k}{M_{2}}\right)^{\frac{1-\sigma_{2}}{\sigma_{2}}}+\alpha(1-\kappa)^{\frac{\sigma_{2}-1}{\sigma_{2}}}\right]
$$

Re-arranging (24)

$$
\left(k / M_{2}\right)^{\frac{1-\sigma_{2}}{\sigma_{2}}}=\frac{(1-\lambda)^{\frac{1}{\sigma_{2}}}}{\lambda} \frac{\kappa}{(1-\kappa)^{1 / \sigma_{2}}}
$$

Re-arranging (92)

$$
\kappa-(1-\kappa)^{1 / \sigma_{2}}\left(\frac{\gamma}{1-\gamma}\right) \alpha(1-\kappa)^{\frac{\sigma_{2}-1}{\sigma_{2}}}=(1-\kappa)^{1 / \sigma_{2}}\left(\frac{\gamma}{1-\gamma}\right)(1-\alpha)(1-\lambda)^{\frac{\sigma_{2}-1}{\sigma_{2}}}\left(k / M_{2}\right)^{\frac{1-\sigma_{2}}{\sigma_{2}}}
$$

Substitute (93) into (94)

$\frac{\kappa}{(1-\kappa)^{1 / \sigma_{2}}}-\left(\frac{\gamma}{1-\gamma}\right) \alpha(1-\kappa)^{\frac{\sigma_{2}-1}{\sigma_{2}}}=\left(\frac{\gamma}{1-\gamma}\right)(1-\alpha)(1-\lambda)^{\frac{\sigma_{2}-1}{\sigma_{2}}} \frac{(1-\lambda)^{\frac{1}{\sigma_{2}}}}{\lambda}\left(\frac{\kappa}{(1-\kappa)^{1 / \sigma_{2}}}\right)$

or

$$
1-\left(\frac{\gamma}{1-\gamma}\right) \alpha(1-\kappa)^{\frac{\sigma_{2}-1}{\sigma_{2}}}\left(\frac{(1-\kappa)^{1 / \sigma_{2}}}{\kappa}\right)=\left(\frac{\gamma}{1-\gamma}\right)(1-\alpha)\left(\frac{1-\lambda}{\lambda}\right)
$$

or

$$
1-\left(\frac{\gamma}{1-\gamma}\right) \alpha\left(\frac{1-\kappa}{\kappa}\right)=\left(\frac{\gamma}{1-\gamma}\right)(1-\alpha)\left(\frac{1-\lambda}{\lambda}\right)
$$

or

$$
1-\left(\frac{\gamma}{1-\gamma}\right) \alpha\left(\frac{1}{\kappa}-1\right)=\left(\frac{\gamma}{1-\gamma}\right)(1-\alpha)\left(\frac{1}{\lambda}-1\right)
$$

Thus

$$
\lambda=\frac{\gamma(1-\alpha) \kappa}{\kappa-\alpha \gamma} \quad \text { with } \quad \frac{d \lambda}{d \kappa}=-\left(\frac{\alpha}{1-\alpha}\right)\left(\frac{\lambda}{\kappa}\right)^{2}<0
$$

Equation (95) shows that $\lambda$ and $\kappa$ always move in opposite direction. Furthermore since $\lambda \leq 1$ and $\kappa \leq 1$, (95) determines the range of permissible values for $\kappa$ is $[\underline{\kappa}, 1]$ and for $\lambda$ is $[\underline{\lambda}, 1]$ where

$$
0<\underline{\lambda} \equiv \frac{\gamma(1-\alpha)}{1-\alpha \gamma}<1
$$

and

$$
0<\underline{\kappa} \equiv \frac{\alpha \gamma}{(1-\gamma)+\alpha \gamma}<1
$$


Combining (93) and (95) and taking logs we reach,

$$
\frac{1-\sigma_{2}}{\sigma_{2}} \ln \left(\frac{k}{M_{2}}\right)=\frac{1}{\sigma_{2}} \ln (1-\lambda(\kappa))-\ln \lambda(\kappa)+\ln \kappa-\frac{1}{\sigma_{2}} \ln (1-\kappa)
$$

This relationship is monotone decreasing (iff $\sigma_{2}>1$ ): an increase in $k$ leads to a fall in $\kappa$ :

$$
\left(\frac{1-\sigma_{2}}{\sigma_{2}}\right)\left(\frac{d k}{k}-\frac{d M_{2}}{M_{2}}\right)=G(\kappa) d \kappa
$$

where

$$
G(\kappa) \equiv\left[\frac{1}{\sigma_{2}(1-\lambda(\kappa))}+\frac{1}{\lambda(\kappa)}\right]\left(\frac{\lambda(\kappa)}{\kappa}\right)^{2}\left(\frac{\alpha}{1-\alpha}\right)+\left[\frac{1}{\kappa}+\frac{1}{\sigma_{2}(1-\kappa)}\right]>0
$$

where $\lambda(\kappa)$ is given by (95).

\section{Remarks on Proposition 3.}

Notice that $k_{1}=\kappa k / \lambda$ and therefore $\widehat{k}_{1}=\widehat{\kappa}-\widehat{\lambda}+\widehat{k}=\left[\frac{k}{\kappa} \frac{\partial \kappa}{\partial k}-\frac{k}{\lambda} \frac{\partial \lambda}{\partial k}+1\right] \widehat{k}$. We now show that the expression inside the squared brackets is positive.

$$
\begin{aligned}
& \frac{k}{\kappa} \frac{\partial \kappa}{\partial k}-\frac{k}{\lambda} \frac{\partial \lambda}{\partial k}+1=\frac{\left(1-\sigma_{2}\right)}{\kappa \sigma_{2} G(\kappa)}+\left(\frac{\alpha}{1-\alpha}\right)\left(\frac{\lambda(\kappa)}{\kappa}\right) \frac{\left(\sigma_{2}-1\right)}{\kappa \sigma_{2} G(\kappa)}+\frac{\kappa \sigma_{2} G(\kappa)}{\kappa \sigma_{2} G(\kappa)} \\
& =\frac{1}{\kappa \sigma_{2} G(\kappa)}+\left(\frac{\alpha}{1-\alpha}\right)\left(\frac{\lambda(\kappa)}{\kappa}\right) \frac{1}{\kappa \sigma_{2} G(\kappa)}+\frac{\kappa G(\kappa)-1-\left(\frac{\alpha}{1-\alpha}\right)\left(\frac{\lambda(\kappa)}{\kappa}\right)}{\kappa G(\kappa)}
\end{aligned}
$$

Using (34)

$$
\kappa G(\kappa)=\left[\frac{\kappa}{\sigma_{2}(1-\lambda(\kappa))}\right]\left(\frac{\lambda(\kappa)}{\kappa}\right)^{2}\left(\frac{\alpha}{1-\alpha}\right)+\left[\frac{\kappa}{\sigma_{2}(1-\kappa)}\right]+\left(\frac{\lambda(\kappa)}{\kappa}\right)\left(\frac{\alpha}{1-\alpha}\right)+1
$$

So

$$
\kappa G(\kappa)-1-\left(\frac{\alpha}{1-\alpha}\right)\left(\frac{\lambda(\kappa)}{\kappa}\right)=\kappa\left[\frac{1}{\sigma_{2}(1-\lambda(\kappa))}\right]\left(\frac{\lambda(\kappa)}{\kappa}\right)^{2}\left(\frac{\alpha}{1-\alpha}\right)+\left[\frac{\kappa}{\sigma_{2}(1-\kappa)}\right]>0
$$

The analysis concerning the capital-labor ratio in the other sector, $k_{2}=\left(\frac{1-\kappa}{1-\lambda}\right) k$, is similar. 


\section{References}

Acemoglu, D. and V. Guerrieri, (2008), "Capital Deepening and Nonbalanced Economic Growth," Journal of Political Economy, 116(3), 467-498.

Alvarez-Cuadrado, F. and M. Poschke, (2011), "Structural Change Out of Agrculture: Labor Push versus Labor Pull" forthcoming in the American Economic Journal: Macroeconomics.

Antras, P., (2004), "Is the U.S. Aggregate Production Function Cobb-Douglas? New Estimates of the Elasticity of Substitution" In: Contributions to Macroeconomics, vol 4. Berkeley Electronic Press.

Antras, P. and R. J. Caballero, (2009), "Trade and Capital Flows: A Financial Frictions Perspective," Journal of Political Economy, 117(4), 701-744.

Ball, D.S., (1966), "Factor-Intensity Reversals in International Comparison of Factor Costs and Factor Use", Journal of Political Economy 74, 77-80.

Balistreri, E. J., C. A. McDaniel, and E. V. Wong, (2003), "An estimation of US industrylevel capital-labor substitution elasticities: support for Cobb-Douglas," The North American Journal of Economics and Finance 14(3), 343-356.

Baumol, William J.(1967), "Macroeconomics of Unbalanced Growth: The Anatomy of Urban Crisis", American Economic Review, LVII , 415-426.

Bentolila, S., Saint-Paul, G., (2003), "Explaining Movements in the Labor Share," In: Contributions to Macroeconomics, vol. 3. Berkeley Electronic Press.

Blanchard, O.J., (1997), "The Medium Run", Brookings Papers on Economic Activity, $1997-2,89-158$.

Behrman, J. R, (1972). "Sectoral Elasticities of Substitution between Capital and Labor in a Developing Economy: Time Series Analysis in the Case of Postwar Chile," Econometrica, 40(2), 311-26.

Buera, F. and J.P. Kaboski (2011), "The Rise of the Service Economy," forthcoming in The American Economic Review.

Caballero, R. J. and M.L. Hammour, (1998), "Jobless growth: appropriability, factor substitution, and unemployment," Carnegie-Rochester Conference Series on Public Policy, 48(1), 51-94.

Caselli, F. and J. Coleman, (2001), "The U.S. Structural Transformation and Regional Convergence: A Reinterpretation", Journal of Political Economy 109, 584-616.

Chanda, A. and C. Dalgaard, (2008), "Dual Economies and International Total Factor Productivity Differences: Channelling the Impact from Institutions, Trade, and Geography," 
Economica, 75(300), 629-661.

Clark, C. (1940), The conditions of economic progress, 3rd edn, Macmillan, London.

Dennis, B. and T. Iscan (2009), "Engel versus Baumol: accounting for structural change using two centuries of U.S. data", Explorations in Economic History, 46 (2), 186-202.

Duarte, M. and Restuccia, D. (2010), "The Role of the Structural Transformation in Aggregate Productivity", Quarterly Journal of Economics 125(1).

Duffy, J., and C. Papageorgiou, (2000), "A cross-country empirical investigation of the aggregate production function specification", Journal of Economic Growth 5, 87-120.

Echevarria, C., (2007), "Changes in Sectoral Composition Associated with EconomicGrowth", International Economic Review, XXXVIII, 431-452.

Foellmi R. and J. Zweimüller, (2008), "Structural Change, Engel's Consumption Cycles and Kaldor's Facts of Economic Growth", Journal of Monetary Economics 55(7), 1317-1328,

Gollin, D., S. Parente and R. Richardson, (2007), "The Food Problem and the Evolution of International Income Levels", Journal of Monetary Economics 54(4): 1230-1255.

Hicks, J. R., (1932), The Theory of Wages, 1st edition, London.

Hutcheson, T.L. (1969), "Factor Intensity Reversals and the CES Production Function", Review of Economics and Statistics, 51, 4, 468-470.

Jorgenson, D. (2007), "35 Sector KLEM"

(http://hdl.handle.net/1902.1/10684 UNF:3:TqM00zRqsatX2q/teT253Q==V1)

Jensen, B.S. (2003), "Walrasian General Equilibrium Allocations and Dynamics in TwoSector Growth Models", German Economic Review, 4, 53-87.

Jones, R.W., (1965), "The structure of a simple general equilibrium models", Journal of Political Economy 73, 557-572.

Kaldor, N., (1963) "Capital Accumulation and Economic Growth", in Friedrich A. Lutz and Douglas C. Hague, eds., Proceedings of a Conference Held by the International Economics Association, London, Macmillan.

Klump, R. and O. De La Grandville, (2000), "Economic Growth and the Elasticity of Substitution: Two Theorems and Some Suggestions," American Economic Review, 90:1, pp. 282-291.

Kongsamut, P., Rebelo, S. and Xie, D. (2001), "Beyond Balanced Growth", Review of Economic Studies 68(4), 869-882.

Krusell, P., L. E. Ohanian, J. Rios-Rull, G. L. Violante (2000), "Capital-Skill Complementarity and Inequality: A Macroeconomic Analysis," Econometrica, 68(5), 1029-1054.

Kurokawa, Y. (2010), "Is a Skill Intensity Reversal a Mere Theoretical Curiosum? Evi- 
dence from the U.S. and Mexico", University of Tsukuba Working Paper.

Kuznets, S. (1966), Modern economic growth, New Haven, CT: Yale University Press.

Larson, D. F,., R. Butzer, Y. Mundlak and A. Crego, Al, (2000), "A Cross-Country Database for Sector Investment and Capital," World Bank Economic Review, 14(2), 371-91.

Laitner, J. (2000), "Structural change and economic growth", Review of Economic Studies, $67,545-561$.

Manuelli, R. and A. Seshadri, (2003) "Frictionless Technology Diffusion: The Case of Tractors," NBER Working Paper No.9604.

Matsuyama, K. (1992), "Agricultural productivity, comparative advantage, and economic growth", Journal of Economic Theory 58(2), 317-334.

Minhas, B.S., (1962), An International Comparison of Factor Cost and Factor Use. Amsterdam: North-Holland Publishing Company.

Miyagiwa, K. and C. Papageorgiou, (2007), "Endogenous Aggregate Elasticity of Substitution", Journal of Economic Dynamics and Control, 31, 2899-2919.

Mundlak, Y., (2000), Agriculture and Econmic Growth: Theory and Measurement, Cambridge, Massachusetts: Harvard University Press.

Ngai, R. and C. Pissarides, (2007), "Structural Change in a Multi-Sector Model of Growth", American Economic Review 97(1), 429-443.

O'Mahoney, M. and M. P. Timmer (2009) "Output, Input and Productivity Measures at the Industry Level: The EU KLEMS Database," Economic Journal, 119(538), 374-403.

Pitchford, J. D. (1960), "Growth and the Elasticity of Substitution", Economic Record 36, 491- 503

Restuccia, D., Yang, D. and Zhu, X. (2008), "Agriculture and Aggregate Productivity: A Quantitative Cross-Country Analysis", Journal of Monetary Economics 55(2), 234-50.

Rosenzweig, M., (1998), "Labor Markets in Low-Income Countries," in Hollis Chenery and T. N. Srinivasan, eds., Handbook of Development Economics, Vol.1, Part II, Chapter 15, 713-762, New York: North-Holland.

Samuelson, P., (1948), "International Trade and the Equalisation of Factor Prices International Trade and the Equalisation of Factor Prices", The Economic Journal, 58, 230, 163-184.

Samuelson, P., (1949), "International Factor-Price Equalisation Once Again International Factor-Price Equalisation Once Again, The Economic Journal, 59, 234, 181-197.

Takayama, A., (1985), Mathematical Economics, 2nd Edition, Cambridge University Press, p. 127. 
Ventura, J., (1997), "Growth and interdependence", Quarterly Journal of Economics 112, $57-84$.

Zuleta, H., Young, A.T., (2010), "Labor's shares aggregate and industry: Accounting for both in a model of unbalanced growth with induced innovation", Manuscript, University of Mississippi. 
Tables and Figures

Table 1. Key variables across countries.

\begin{tabular}{|c|c|c|c|c|c|}
\hline & $Y / L$ & $K^{n a} / L^{n a}$ & $K^{a} / L^{a}$ & $L^{a} / L$ & $K^{a} / K$ \\
\hline Rich 5 & 18,118 & 79,338 & 92,322 & $5.00 \%$ & $5.70 \%$ \\
\hline Poor 5 & 807 & 5,577 & 172 & $78.00 \%$ & $11.00 \%$ \\
\hline Ratio & 22 & 14 & 537 & $1 / 16$ & $1 / 2$ \\
\hline Mean & 8,084 & 36,194 & 26,210 & $29.19 \%$ & $7.27 \%$ \\
\hline Std. Dev. & 6,094 & 29,474 & 33,842 & $24.36 \%$ & $3.53 \%$ \\
\hline Min & 529 & 1,297 & 23 & $2.00 \%$ & $1.76 \%$ \\
\hline Max & 20,717 & 99,492 & 125,618 & $84.00 \%$ & $16.37 \%$ \\
\hline Coeff. Var & 0.75 & 0.81 & 1.29 & 0.83 & 0.49 \\
\hline
\end{tabular}

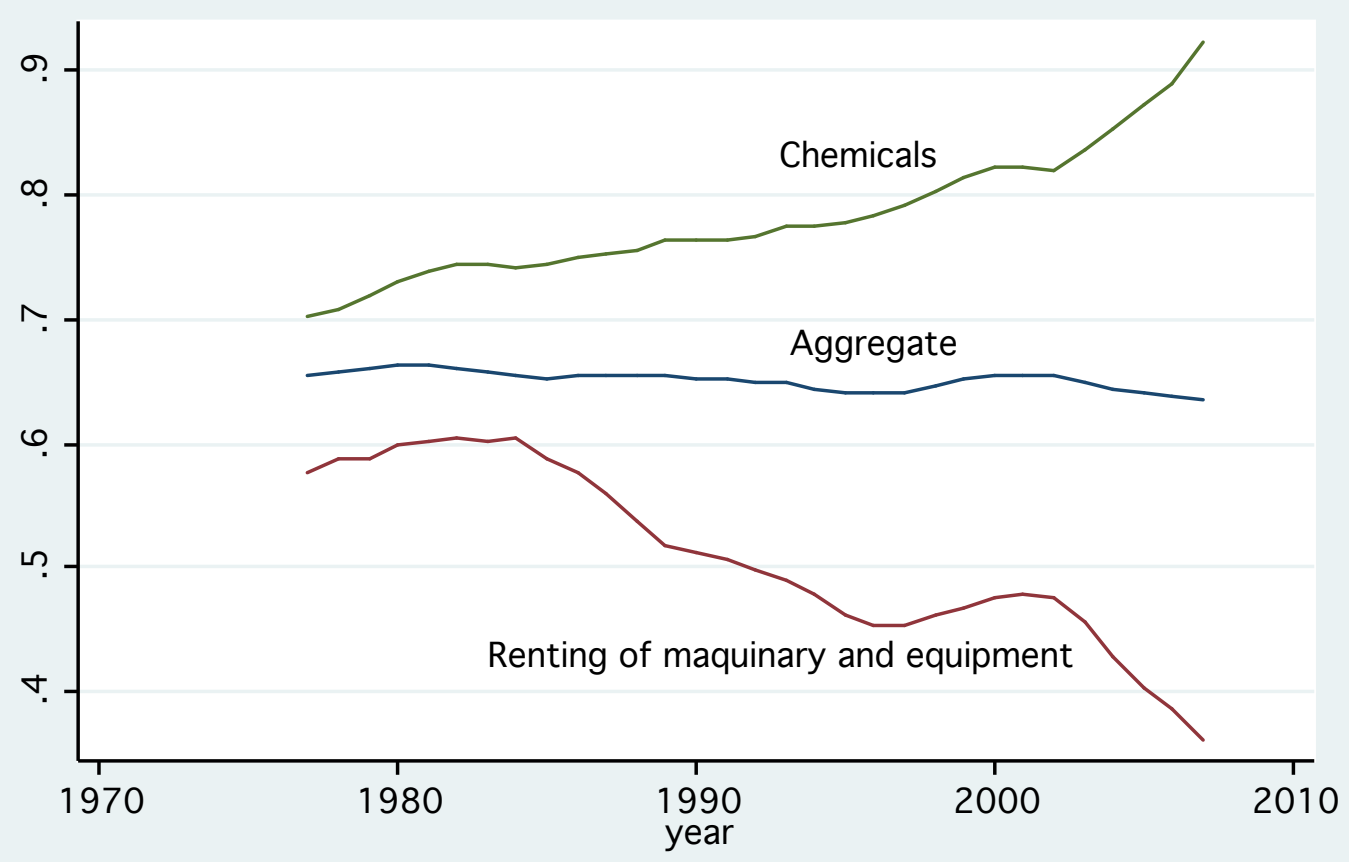

Figure 1. Labor income shares: aggregate and selected industries Source: EU KLEMS database http://www.euklems.net/ 


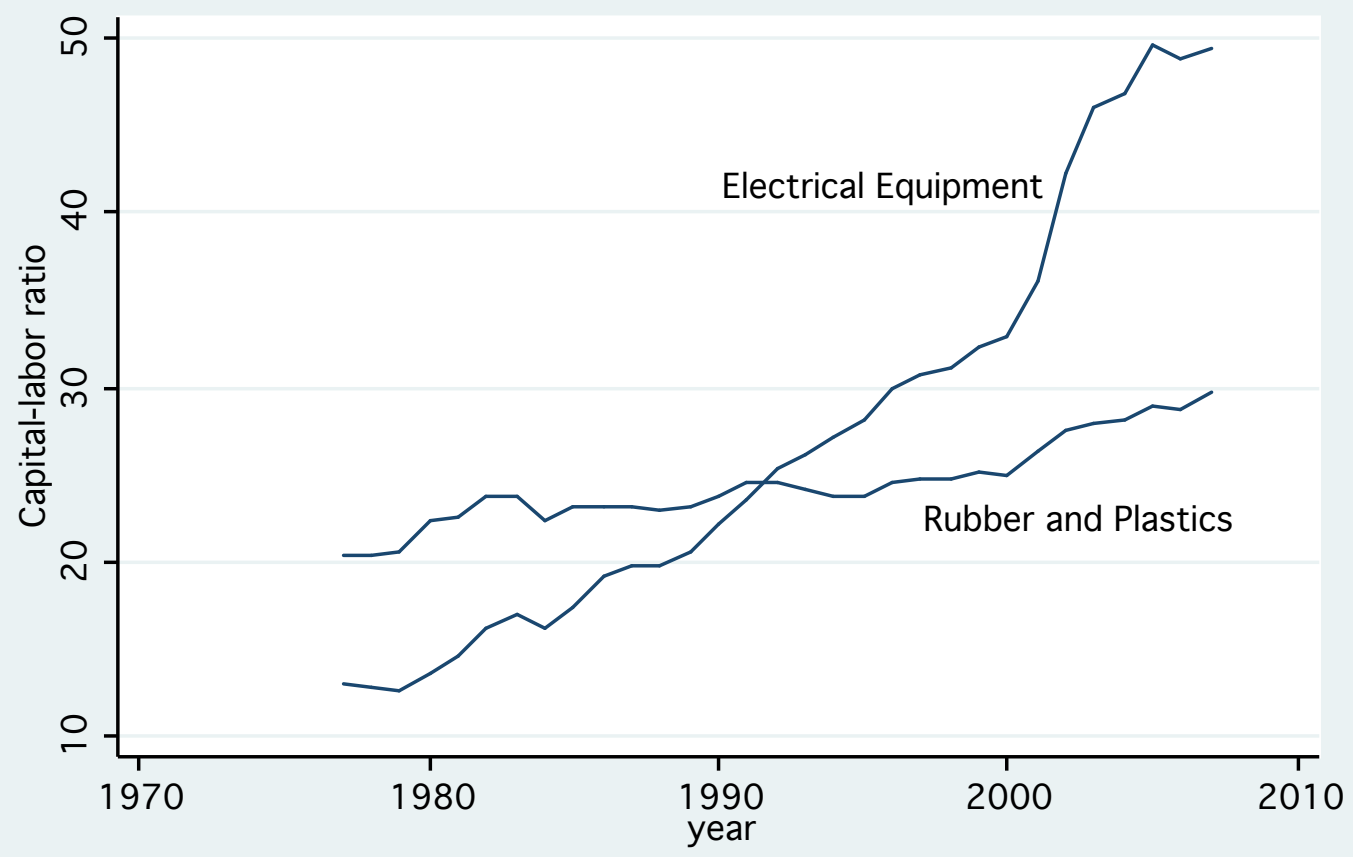

Figure 2. US Capital-labor ratio: Selected industries. A Capital-intensity reversal. Source: EU KLEMS database http://www.euklems.net/

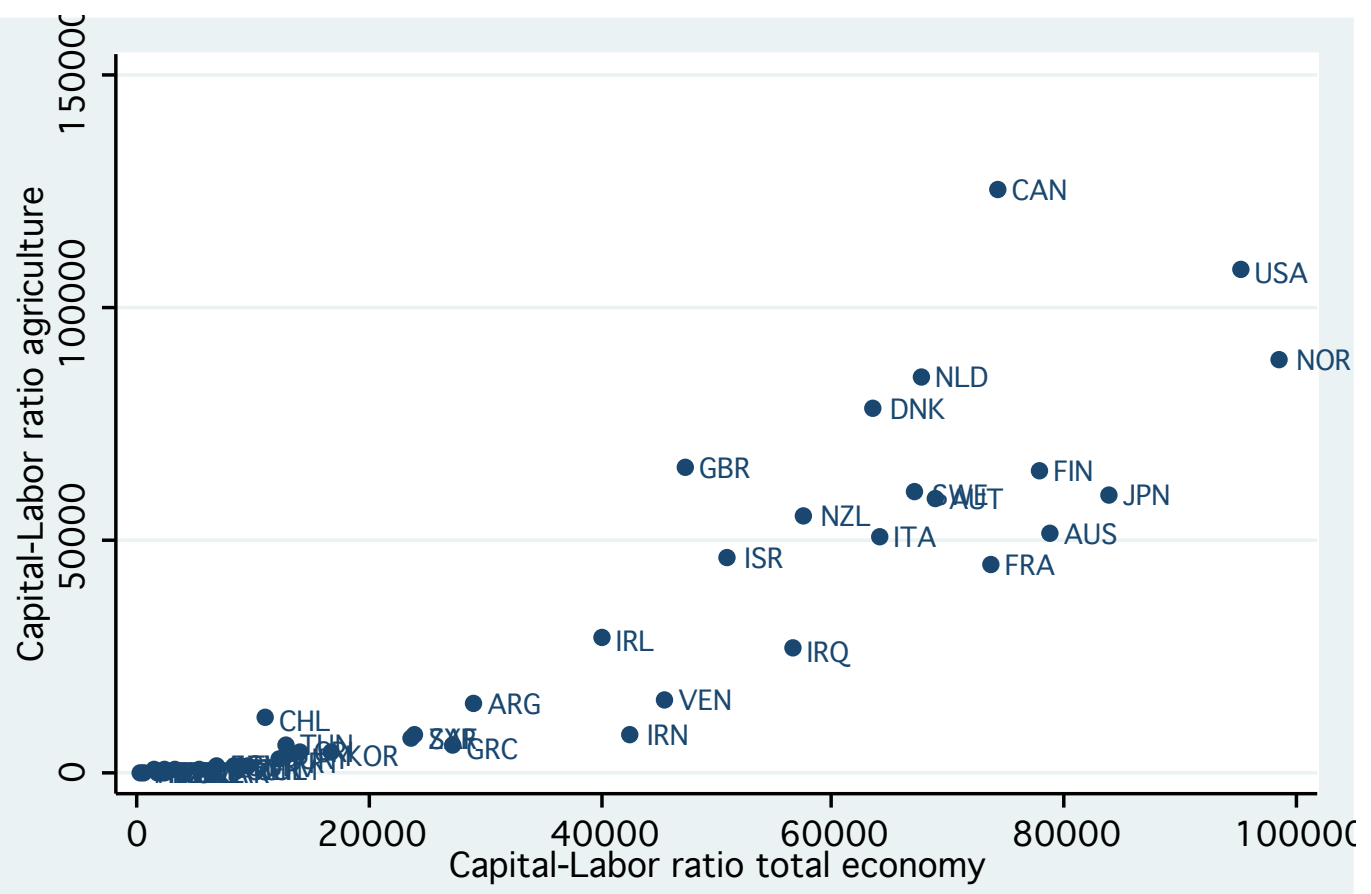

Figure 3. Capital-Labor ratio: Agriculture vs. total economy. Source: Crego et al (2000) Duarte and Restuccia (2010) and GGDC Total economy database 


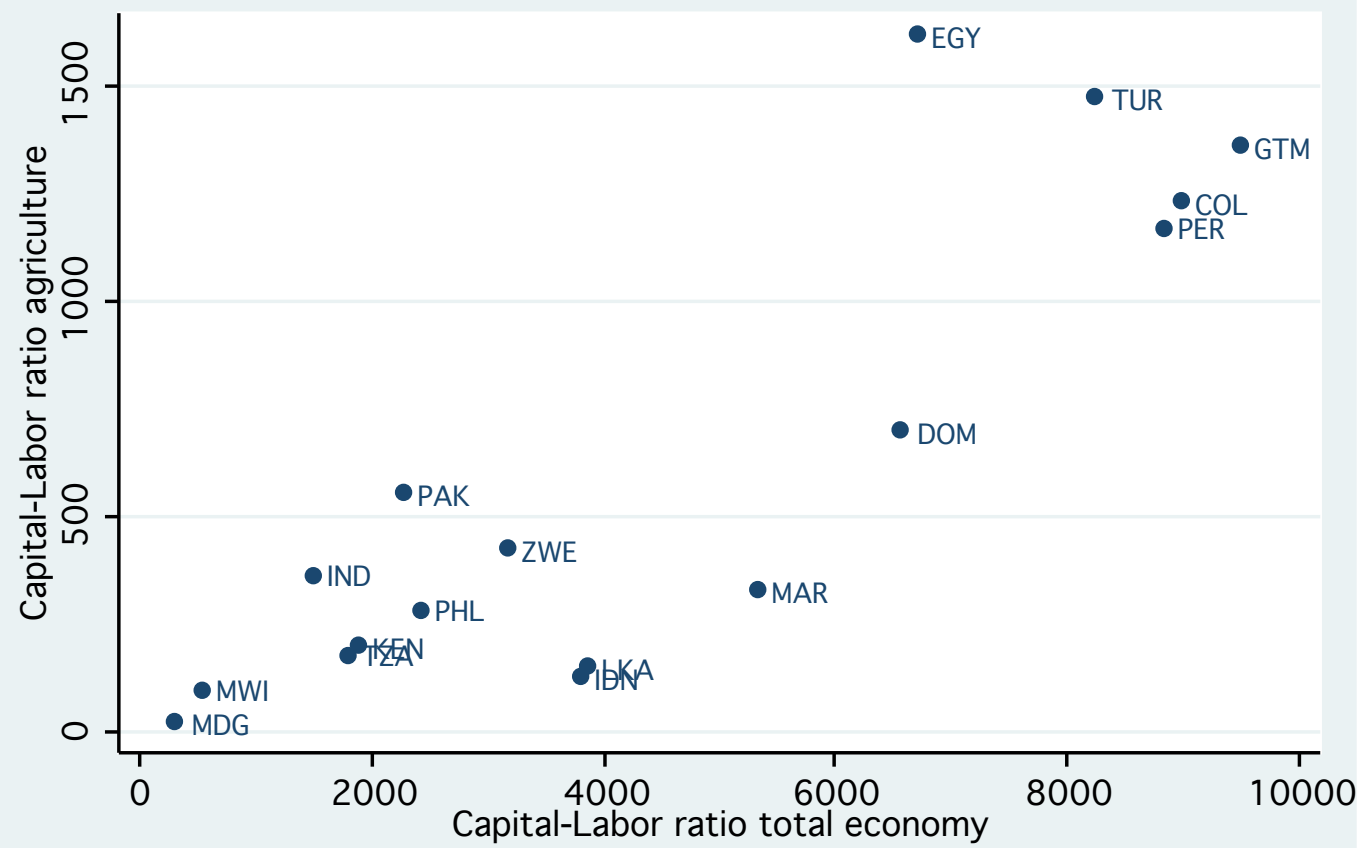

Figure 4. Capital-Labor ratio for developing countries: Agriculture vs. total econom Source: Crego et al (2000) Duarte and Restuccia (2010) and GGDC Total economy database

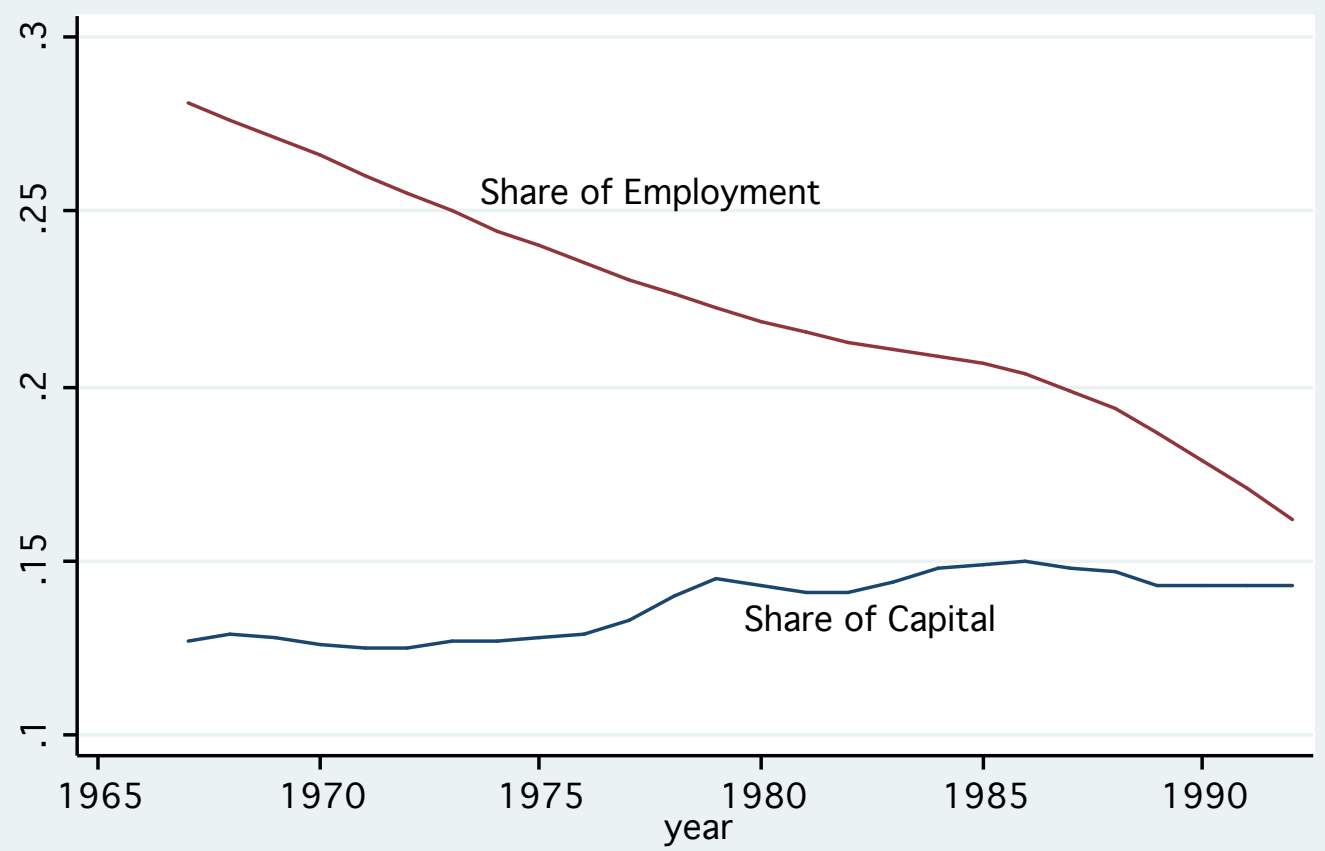

Figure 5. Shares of employment and capital in agriculture : Chile.

Source: Crego et al (2000) and Duarte and Restuccia (2010) 


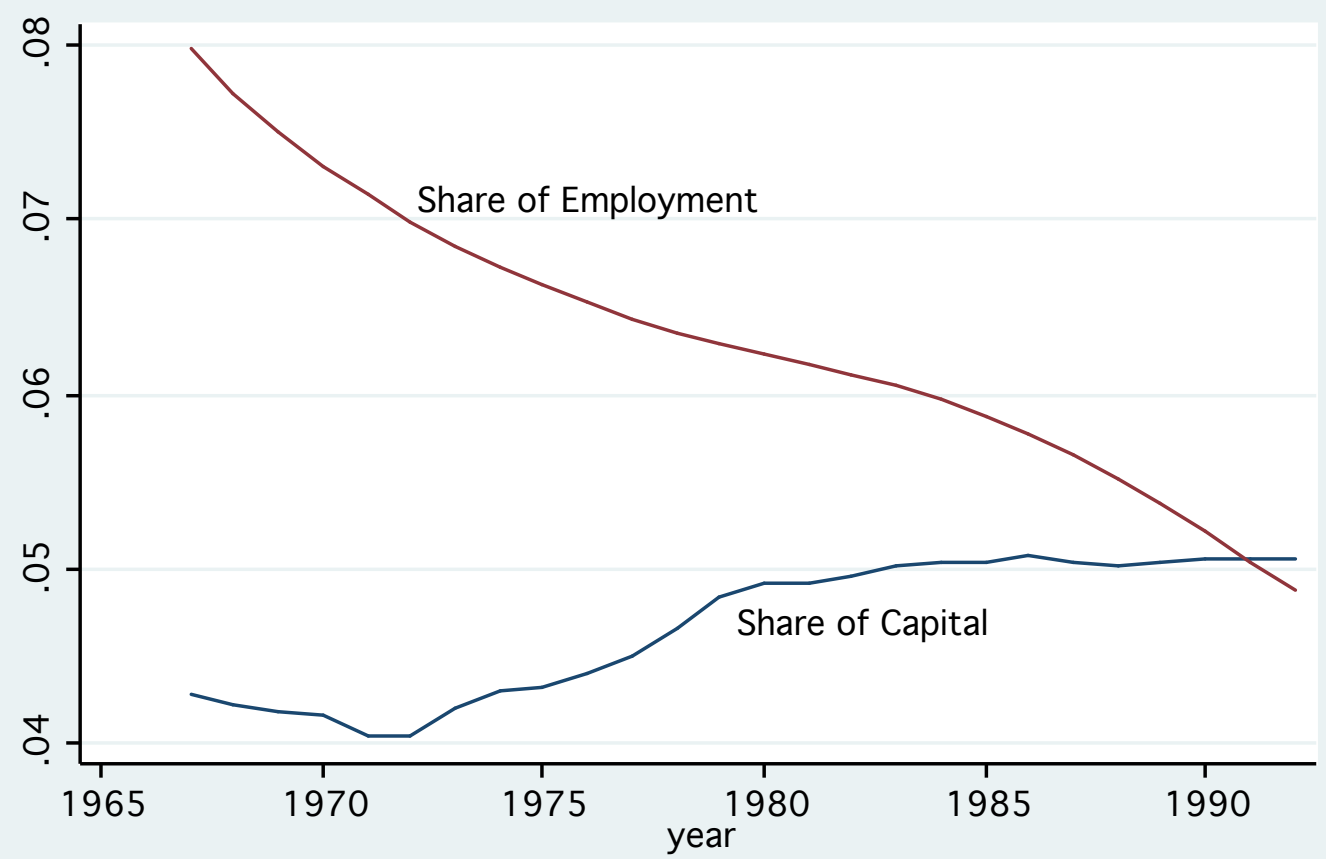

Figure 6. Shares of employment and capital in agriculture : The Netherlands. Source: Crego et al (2000) and Duarte and Restuccia (2010) 


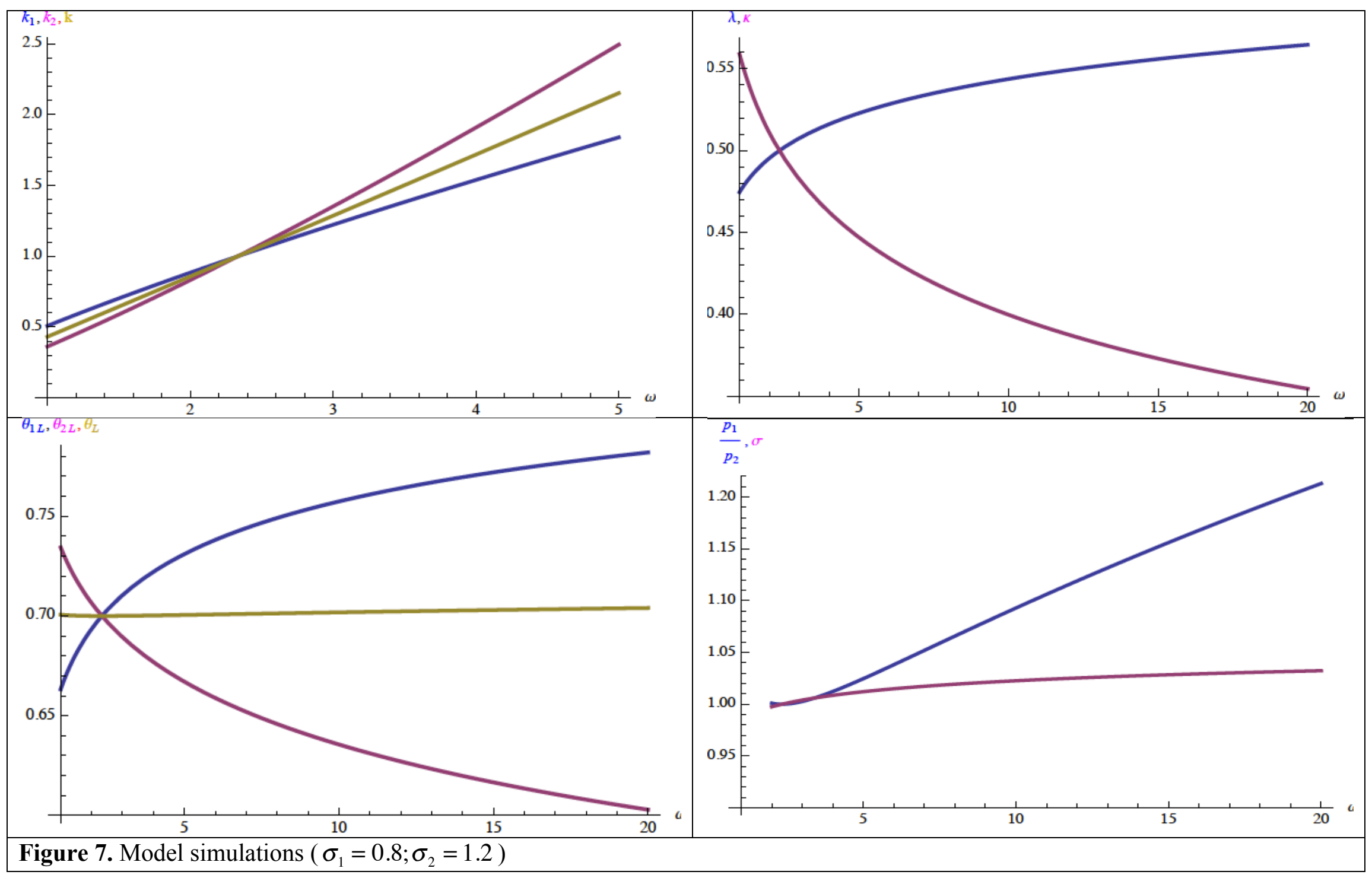


